NBSIR 84-2918

\title{
Fortran 77 Computer Program for Test Procedure Calculations of Vented Heaters
}

Robert A. Wise

Fletcher C. Parsons

U.S. DEPARTMENT OF COMMERCE

National Bureau of Standards

National Engineering Laboratory

Center for Building Technology

Building Equipment Division

Washington, D.C. 20234

April 20, 1984

Issued Sept. 1984

Prepared for:

United States Department of Energy

Washington, D.C. 20585 



\section{FORTRAN 77 COMPUTER PROGRAM FOR TEST PROCEDURE CALCULATIONS OF VENTED HEATERS}

Robert A. Wise

Fletcher C. Parsons

\section{U.S. DEPARTMENT OF COMMERCE}

National Bureau of Standards

National Engineering Laboratory

Center for Building Technology

Building Equipment Division

Washington, D.C. 20234

April 20, 1984

Issued Sept. 1984

Prepared for:

United States Department of Energy

Washington, D.C. 20585

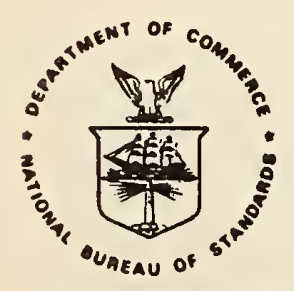

U.S. DEPARTMENT OF COMMERCE, Malcolm Baldrige, Secretary NATIONAL BUREAU OF STANDARDS, Ernest Ambler, Director 



\section{ABSTRACT}

The Fortran 77 computer program described in this report is to be used to calculate results from tests run on vented heaters. The Department of Energy recently published a revised test procedure for such heaters but which contains a simplified method for testing with a number of testing options that allow more detailed tests to be run. The new procedure also provides for the testing of units with manual controls of two types, modulating controls of two types, and the testing of units incorporating thermal stack dampers as well as electro-mechanical dampers. Once input selections have been made, the program performs the calculations required and prints out the results.

Key words: computer program; energy; test procedure; vented heater; furnace. 
TABLE OF CONTENTS

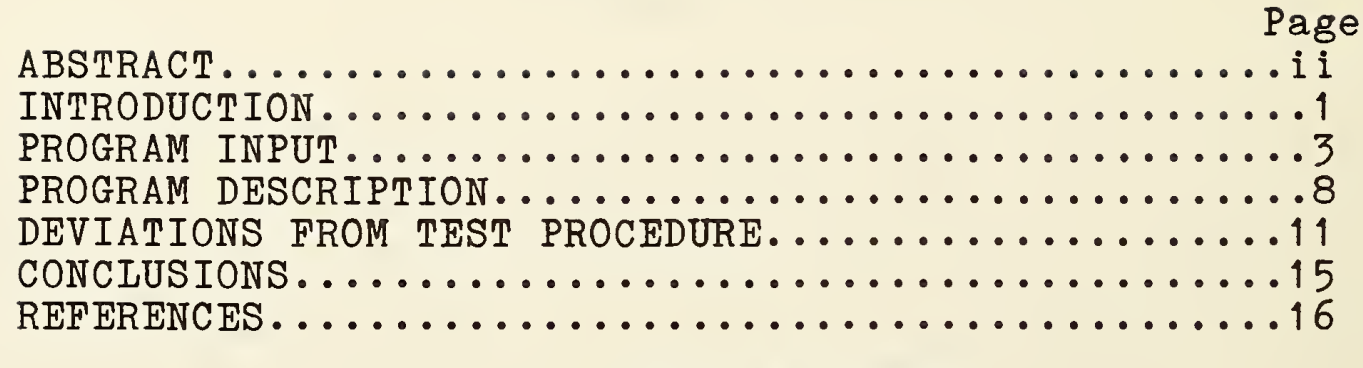

LIST OF TABLES

TABLE 1. Input variables..................

IIST OF FIGURES

FIGURE 1. Program input form................

FIGURE 2. Input-variable flow chart............10

FIGURE 3. Program flow diagram..............12

IIST OF APPENDIX

APPENDIX A. Computer Program Listing............

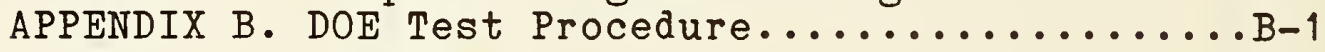
APPENDIX C. Examples....................... 
Vented heaters are home heating devices that exhaust the products of combustion to the outside and that furnish warmed air to a living space without duct connections to distribute the heated air. They may use electrically driven fans or blowers to circulate the air from the heater to the living space.

In 1978 the Department of Energy (DOE) published in the Federal Register [1]* a Final Rule test procedure to be used to test vented heaters. This procedure was almost identical to the one for furnaces published at the same time. The rule required that the results of specified tests be used to calculate the estimated annual operating cost, the annual fuel utilization efficiency (AFUE), and the estimated regional annual operating cost. The National Bureau of Standards (NBS) published a report [2] that described the rule as it was proposed to DOE with a Fortran computer program to perform the many and complicated calculations needed to determine the required efficiency and cost information. In 1982, NBS published another report [3] describing a proposed modification to the furnace and the vented heater test procedures to test these products when they incorporate modulating type controls. This publication also contained a Fortran computer program, titled FBVH, which is the basis for the revised program in this report.

On March 28, 1984, DOE published a revised final rule test procedure for furnaces, heaters, and vented heaters [4]. The vented heater section provides an entirely new test method for the determination of annual fuel utilization efficiency (AFUE) and the estimated operating cost per million Btu output. It deletes the requirements for determination of annual operating costs.

The new procedure is quite different from the one it replaces in that it allows the omission of time consuming and computationally complicated heat-up and cool-down tests. The tests are replaced with a formula that applies constant multiplying factors to the steady-state efficiency, to the stack and flue draft factors, to the pilot light energy ratio and to the loss in efficiency due to jacket losses for floor furnaces. The coefficients were determined from a multiple regression of test data on a number of units that were tested using the old DOE test procedure [5]. The newly published procedure also provides test methods for evaluating units with two different types of modulating controls (step modulating and two stage) and two types of manual controls: those with just "on"-"off" control and those

* Numbers in brackets pertain to references listed on page 17. 
that can be adjusted for the fuel burning rate as well as "on" and "off." Background information on the test method for modulating controls may be found in Reference [6]. Finally, a test method to be used for units incorporating thermal dampers has been added to the procedure. The thermal damper test uses a new off-loss tracer gas type of test. The tracer gas test is also allowed to be used as an option for the measurement of the off period heat losses of units without thermal dampers. When the off-loss method is selected or required, the simplified AFUE calculation is not used. Instead, a cycling part load efficiency is calculated and used in determining AFUE. For manual type controls a psuedo part-load efficiency is calculated using only the on-time infiltration loss term.

This report describes a Fortran 77 computer program (Appendix A) to be used to calculate the results of tests performed on vented heaters. The program serves two purposes: it provides computerized calculations of a complex test procedure, and it explicitly defines the test method to be used. The program will be directly useful to some manufacturers or laboratories involved in testing, it can be used to check programs already written, or it can serve as the basis for writing similar programs in other computer languages. The explicit definition can be useful to test users in resolving questions that arise regarding the exact meaning of the wording of the published procedure. The steps to be followed and the meanings of the word descriptions are clarified with a computer program that covers all permitted calculation steps and sequences. 
Appendix $B$ contains the final rule regulation published by DOE on March 28, 1984 [4]. Apendix B is different than the DOE publication in that only the pages relating to the testing requirements of vented heaters are included and the columms on the pages have been rearranged to make the text and formulas flow in a sequential and logical order. This publication specifies the test methods, the data required, and the calculations necessary to arrive at the AFUE and the dollars per million Btu output. Appendix A contains a Fortran 77 program which performs these calculations. This report will not attempt to describe the details of the test but rather describe how the data are entered into the program and how the calculations are performed.

The Fortran program is written so that input information is taken from a previously written data file stored in the computer. An example of such a file is on page C2 of Appendix C. In the Univac computer at NBS, the data is in an element of a file. After a response to the instruction given on line 340 of the program listing in Appendix A is entered, the computer reads the lines in the file (element) one by one as READ statements are encountered. Users of the program may want to modify this input structure to meet the requirements of the computer being used. Most of the READ statements of the program use the free field format, $\operatorname{READ}(6, *)$ where logical unit "6" is the terminal or the "@ADD"ed element. Integer or real numbers may be entered indiscriminately and the number of decimal places in the numbers is immaterial. Spaces or commas may be used to separate entered values. Some compilers may not accept this type read statement so the program may have to be modified with additional FORMAT lines.

Figure 1 is an input data sheet which may be used to record test data prior to entering the data into the computer input file. An example of a data sheet with handwritten test result measurements is shown on page $C 1$ of Appendix C. The measurement units or dimensions to be used for each entry are given directly under the name of the data value to be entered. Although some of the units are not specified in the test procedure, the units on the input form have been selected to conform to the numerical constants and equations of the test procedure. The option of entering temperatures in fahrenheit or in celsius has been provided since converting while entering data is inconvenient. If celsius value is entered as the ambient temperature, then the conversion is performed on all temperature measurements entered on that line. In the same manner, the option of entering barometric pressure in inches of mercury or in milibars has been provided and if barometric pressure was not known or recorded, 0.0 may be entered. The program will then use a default value of 30 inches of mercury. 
Title \#1

Titie \#2

\begin{tabular}{|c|c|c|c|c|c|}
\hline $\begin{array}{c}\text { System } \\
\#\end{array}$ & $\begin{array}{c}\text { Fuel } \\
\#\end{array}$ & $\begin{array}{c}\text { Control } \\
\#\end{array}$ & $\begin{array}{c}\text { Option } \\
\#\end{array}$ & $\begin{array}{c}\text { Fuel Cost } \\
\text { c/Therm. }\end{array}$ & $\begin{array}{c}\text { Elect. Cost } \\
\text { c/kih }\end{array}$ \\
\hline & & & & & \\
\hline
\end{tabular}

\begin{tabular}{|c|c|c|}
\hline $\begin{array}{c}\text { Pilot } \\
\text { Btulmin* }\end{array}$ & $\begin{array}{c}\text { Elect. } \\
\text { kW* }\end{array}$ & $\begin{array}{c}\text { Jacket } \\
\text { Ioss, of } *\end{array}$ \\
\hline & & \\
\hline
\end{tabular}

NOTE \#1. Enter 50\% input rate values if manual control, type \#4. \#2. * =enter 0.0 if not measured

\begin{tabular}{|c|c|c|c|c|c|}
\hline $\begin{array}{l}\text { Fuel Input } \\
\text { et,u/min. }\end{array}$ & $\begin{array}{l}\text { Room Amb. } \\
\text { F or C }\end{array}$ & $\begin{array}{l}\text { Stack Temp. } \\
F \text { or } \mathrm{C}^{*}\end{array}$ & $\begin{array}{l}\text { Flue Temp. } \\
F \text { or } \mathrm{C}^{*}\end{array}$ & C02 Stack & C02 Flue \\
\hline es & 117 & at se & $1 \mathrm{~d}$ & inout & e. \\
\hline
\end{tabular}

Enter next line only if with damper and off-loss not measured.

\begin{tabular}{|c|c|c|}
\hline $\begin{array}{c}\text { Stack Area } \\
\text { sq. in. }\end{array}$ & $\begin{array}{r}\text { Damper area } \\
\text { sq. in. }\end{array}$ & $\begin{array}{c}\text { Angle } \\
\text { deg. }\end{array}$ \\
\hline & & \\
\hline
\end{tabular}

Enter next line only if draft measured (Do), ootion $\not 22$.

\begin{tabular}{|c|c|c|c|c|c|}
\hline $\begin{array}{l}\text { Barometer } \\
\text { "Ig or mb" }\end{array}$ & $\begin{array}{l}\text { Gas Temp. } \\
\text { F or C }\end{array}$ & $\begin{array}{l}\text { Gas Conc. } \\
\text { o or pom }\end{array}$ & $\begin{array}{l}\text { Gas Flow } \\
\text { cu.ft./min }\end{array}$ & $\begin{array}{l}\text { Trac.Conc. } \\
\text { \% or opm }\end{array}$ & $\begin{array}{c}\text { Flue Temp. } \\
\text { F or } \mathrm{C}\end{array}$ \\
\hline & & & & & \\
\hline
\end{tabular}

Enter next Iines only if measured high fire off-loss measured.

\begin{tabular}{|l|l|l|l|}
\hline $\begin{array}{l}\text { Barometer } \\
\text { "Ig or mb* }\end{array}$ & $\begin{array}{l}\text { Gas Temp. } \\
\text { F or C }\end{array}$ & $\begin{array}{l}\text { Gas Conc. } \\
\text { \% or oom }\end{array}$ & $\begin{array}{l}\text { Gas Flow.ft./min } \\
\text { cu.ft. }\end{array}$ \\
\hline
\end{tabular}

\begin{tabular}{|c|c|c|}
\hline $\begin{array}{c}\text { Meas } \\
\frac{H}{H}\end{array}$ & $\begin{array}{c}\text { Trac.Conc } \\
\text { \% or pom }\end{array}$ & $\begin{array}{c}\text { Flue Temp. } \\
\text { F or C }\end{array}$ \\
\hline$\frac{1}{2}$ & & \\
\hline 3 & & \\
\hline 4 & & \\
\hline 5 & & \\
\hline 6 & & \\
\hline 7 & & \\
\hline$\frac{5}{5}$ & & \\
\hline $1 C$ & & \\
\hline
\end{tabular}

Enter next lines only if reduced fire off-loss measured.

\begin{tabular}{|c|c|c|c|}
\hline $\begin{array}{l}\text { 3arometer } \\
\text { "Hg or mb" }\end{array}$ & \multicolumn{2}{|c|}{$\begin{array}{l}\text { Gas Temp. } \\
\text { F or C }\end{array}$} & $\begin{array}{l}\text { Gas Con } \\
\text { \& or pp }\end{array}$ \\
\hline & & & \\
\hline 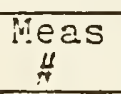 & $\begin{array}{l}\text { Trac.Conc. } \\
\text { \% or pom }\end{array}$ & & $\begin{array}{l}\text { e Temp. } \\
\text { or C }\end{array}$ \\
\hline 1 & & & \\
\hline 2 & & & \\
\hline 3 & & & \\
\hline 4 & & & \\
\hline 5 & & & \\
\hline 6 & & & \\
\hline 7 & & & \\
\hline 8 & & & \\
\hline 0 & & & \\
\hline 10 & & & \\
\hline
\end{tabular}


After the input information from the "Input form", Figure 1, is transferred to a data input element in the computer, the computer program VENT, Appendix A, can be run. The data relating to the tests that were run is READ from the stored data file, or element, line by line by the Fortran READ statements at the following line numbers.

Line 380

Title. This entry may contain up to 80 characters of alphanumeric written material such as a title, test date, manufacturer or model information etc.

Line 380

Title. The second entered title line may contain additional information not included in line 1, or a blank line may be entered.

Line 470

Conditions. This line must contain six numeric entries of four integer numbers followed by two real numbers. The integer numbers select the type of unit being evaluated and the type of fuel used from Tables 1 and 2 of the test procedure, the type control incorporated in the unit tested, and the optional test procedures used. For convenience in reading the program, the meanings of the input selection values are included as comments on lines 480 to 650. The two real numbers are the costs of the fuels used. The cost of fuel is made as an input READ rather than as a fixed DATA statement line in the program to remind the user to enter the latest cost values published by DOE in the Federal Register. The costs of \#1 oil, manufactured gas, and butane are not included in the DOE published costs. It is suggested that the cents per therm of natural gas be used for manufactured gas, that the cents per gallon of \#2 oil be used for \#1 oil, and that cents per gallon of propane be used for butane.

\section{Line 730}

Auxiliary data. Three real number entries are entered on this line. Note that the pilot light fuel input rate is in Btu per minute rather than the more customary Btu/hour. The Btu/min. units were selected because the only time a gas fuel input rate dimension is given in the test procedure the units are in Btu /min. This is in section 4.3.3 of the test procedure where the burner fuel input rate is used in calculating off-losses. The program user can change the data input units to Btu/hr. by dividing the entered values of the pilot and the burner fuel input rates by 60.0 as an added statement or adding a "/60." in Iines 2210, 3370, and 3380 .

The jacket loss in percent should be entered as 0.0 for units installed indoors. For floor furnaces (heaters) the measured value using ANSI standard Z21.48-1976 for "vented floor furnaces" multiplied by 0.712 should be used. 
Line 900

The remaining lines in the input data file contain measured test data values. The only test data entries always needed are READ on line 900 of the program (the fifth line on the input form, Figure 1.) This line must be entered and it must contain six real number test data results. However, if the specified tests on the tested unit do not require that some of the values be measured, i.e., flue temperature on units having draft diverters, a value of 0.0 is entered. Note that the fuel input value is in Btu/min (see the discussion above regarding the pilot light fuel input rate entry.) If the unit tested has a manual type control with adjustable fuel input rate, the data entered as "Fuel input" would be the $50 \%$ fuel input rate actually used.

\section{Line 980}

The next line on the input form is the same as the previous line except that the test values are those measured at the reduced fuel input rate when the unit tested has a modulating type control. The line is skipped if the control is non-modulating.

\section{Line 1050}

The physical measurements of the stack damper are entered if a damper is included in the unit being tested. This applies only to electro-mechanical dampers; thermal dampers must be tested using the off-loss tracer gas test. The data must be entered for all units with dampers unless the option of off-loss testing has been taken, in which case the line of data is skipped.

\section{Line 1140}

The next line of data is skipped on the Input Form unless testing option \#2 was selected, "Optional procedure for determining "Dp" for vented home heating equipment." If the option was taken, data from the tracer gas test of section 3.6 in the test procedure is used.

\section{Lines 1260 and 1300 , also 1420 and 1460}

The last two groups of input data values on Figure 1 are used only if the tracer gas off-loss testing option \#3 was selected. If the optional procedure (mandatory for units with thermal dampers) is used, the test condition input values are entered on the first line followed by ten measurements of tracer gas concentration and flue gas temperature. The first measured pair of values would have been taken 30 seconds after the fuel input was turned off after steady-state conditions had been attained. The next nine pairs of values would have been taken at one minute intervals after the first readings.

Both groups of test data, high-fire and reduced-fire, will be entered if the tested unit has a two-stage modulating type control. For single-stage 
non-modulating controls only the high-fire values are entered, and for step-modulating type controls only the reduced fire test data are taken and entered.

As the program is structured, a minimum of five lines of input data must be entered and a maximum of 28 Iine entries may be used. It is possible to have only four test data values or as many as 39 measured test data values. 


\section{PROGRAM DESCRIPTION}

The 401 line Fortran 77 program of Appendix A contains 110 comment lines, three subroutines, and one function. The function, lines 4060 to 4090 , converts temperature value units. Following are the starting lines of the subroutines along with a description of their use.

\section{Line 3720}

Subroutine SSIOSS calculates the steady-state test results. Air mass-flow rate ratio, RTF; S/F ratio, SFR; sensible heat loss, QSSS; and steady state efficiency, EFYSS, are calculated. The higher heating value, HHV; air to fuel ratio, AFR; and latent heat loss, QL, are assigned table values. This subroutine is similar to SENLOS which was used in previously published Fortran programs.

\section{Line 3460}

Subroutine WGHT provides the values needed for modulating furnace evaluation. The balance point temperature is calculated. The average outside air temperatures, when in the high and reduced firing rate modes, and the ratio of time during the heating season that the unit is in its low firing rate mode are selected from the values listed in Table 3 of the test procedure. WGHT is similar to the subroutine WEIGHT used in the program FBVH [3] except that 16 values of "Heat output ratio" from Table 3 are used as look-up table values.

\section{Line 3270}

Subroutine LOSOFF is used when the optional test procedure for measuring off-losses is used. The subroutine calculates latent and sensible heat losses during the off period when the unit is cycling. LOSOFF is similar to the subroutine OFFLOS of program FBVH except that only 10 rather than 20 measurements are used. Also, the barometric pressure, $\mathrm{Pb}$, required by the test procedure is incorporated into the equations.

Input to the program was covered in the previous section but Table 1 on the following page of this report should be helpful in comparing the input variable names in the test procedure with the names used in the program. The number of the section of the test procedure, Appendix $B$, where the variable name first appears is also listed along with the units that apply to the variable. The units are not necessarily in the section where the name first appears. The subscripts and number-type to alpha letter convention of Fortran make the renaming neccessary. Figure 2 shows a flow chart of the inputs to the program. The chart is self explanatory and clearly illustrates 


\section{TABLE 1}

INPUT VARIABLES FOR VENTED HEATER TEST PROCEDURE

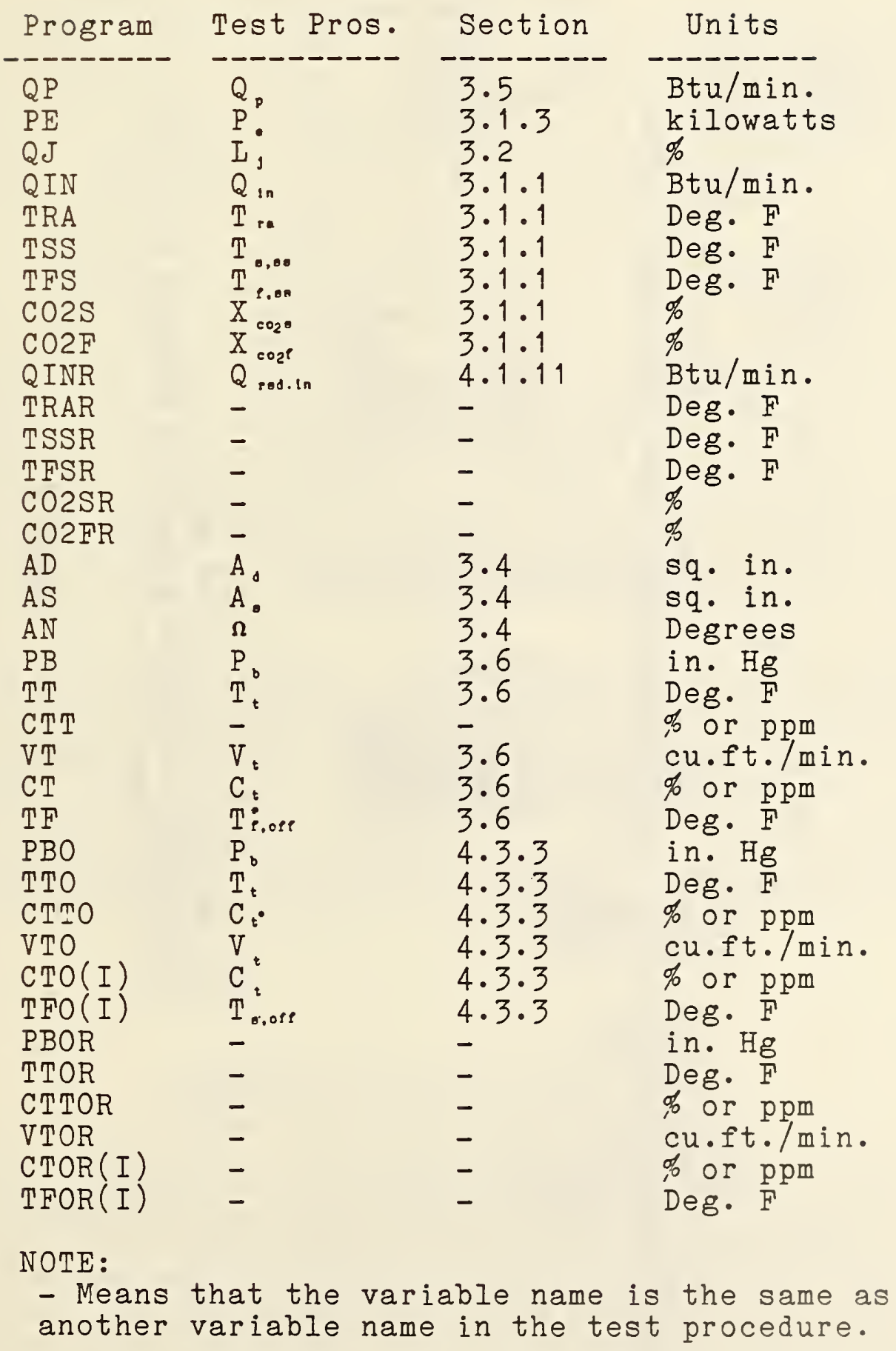




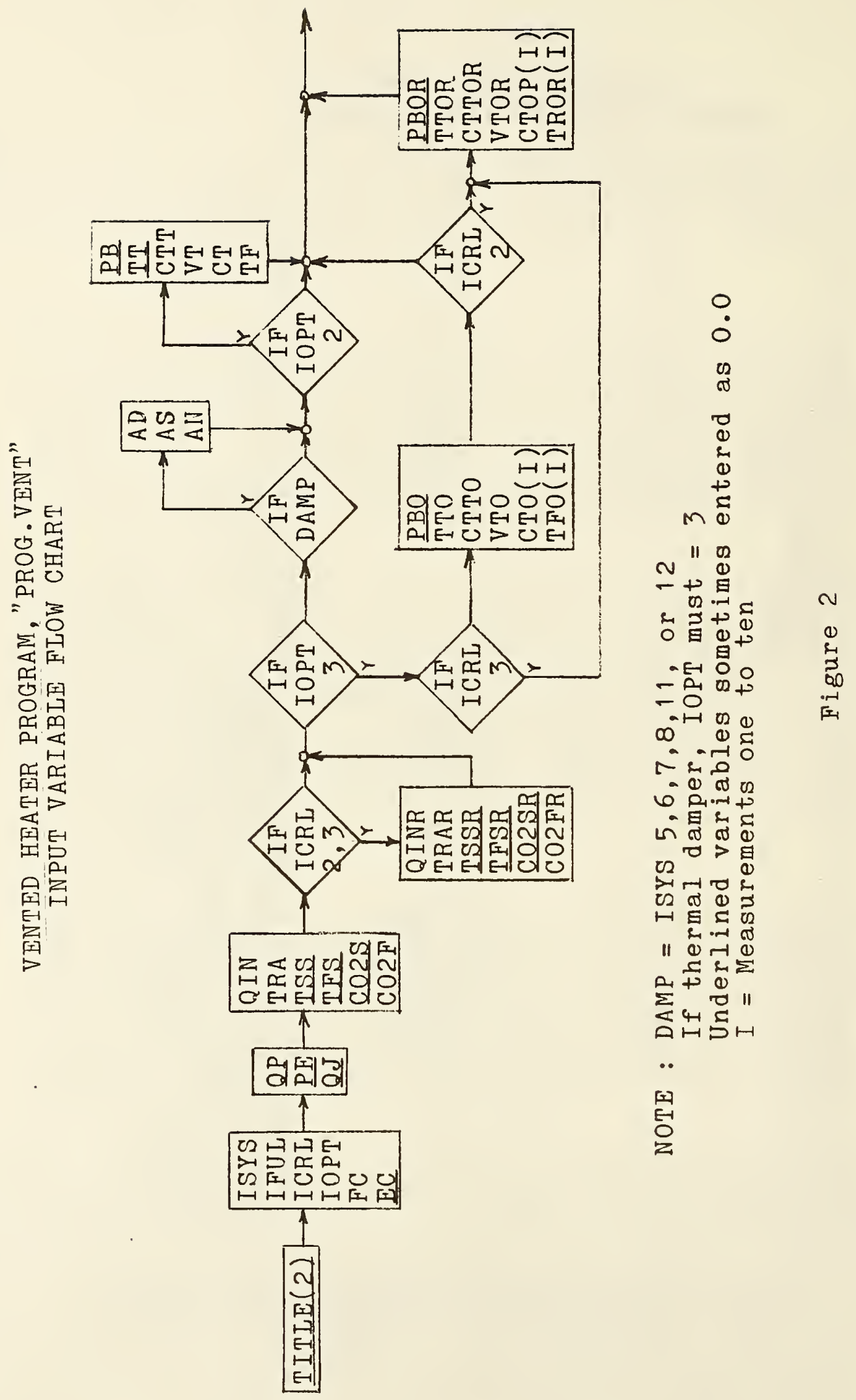


the various inputs required for the different control types and options selected. The input section of the program, Iines 380 to 1560 covers all of the inputs, the various options, the conversions of temperatures and barometric pressure, and the printout of the input titles, program selections, and test data. No checks have been incorporated to assure that the data entered fall within acceptable or normal ranges and no check for incorrectly entered data has been made.

After the the data have been read, Iines 1560 to line 3050 calculate the results needed to obtain the values required by the test procedure, section 430.22, pages 12156-7 (AFUE and estimated operating cost per million Btu output.) The calculation portion of the program can be seen in the simplified flow chart of Figure 3. The chart shows only the subroutine calls and a few intermediate variables and omits most calculations and many intermediate values. The flow chart and the comments in the program itself should be sufficient to explain the steps taken and the conditional evaluations that are made to perform the needed actions. Only two checks have been included in the program. The one at lines 2010,2020 is made to assure that "Do" is not negative or greater than one. If greater, "Do" is made equal to one and if less than 0.0 it is changed to 0.0. The formula in Section 4.4 used to calculate "Do" is not a rigorous mathematical evaluation so it can generate values that have no physical significance. At lines 2370, 2380, another check is made to make sure that the draft factors, Df and Ds, are not assigned values greater than one. Again, if greater than one, it is made equal to 1.0 .

The calculated value, "Do", is printed out along with the input measurements of the damper, and "Df" and "Ds" are printed out when the simplified AFUE calculation is used. When modulating type controls are tested, the heat fractions and balance point temperature are printed. When the tracer gas test for off-losses is used, the "on" and "off" infiltration and sensible heat losses are printed as output. The main output of the program is the steady state efficiency and the two results required by the test procedure, AFUE and cost per million Btu.

\section{DEVIATIONS FROM TEST PROCEDURE}

The Fortran program of this report was written to conform as closely as possible to the published test procedure. In several instances there are differences due to typographical errors or inadvertent omissions of needed changes that were not included in the procedure as published. The program was written with as many errors corrected as possible. The deviations are in sections of Appendix 0 of the test procedure (Appendix $B$ of this report). The section numbers and changes are as follows: 


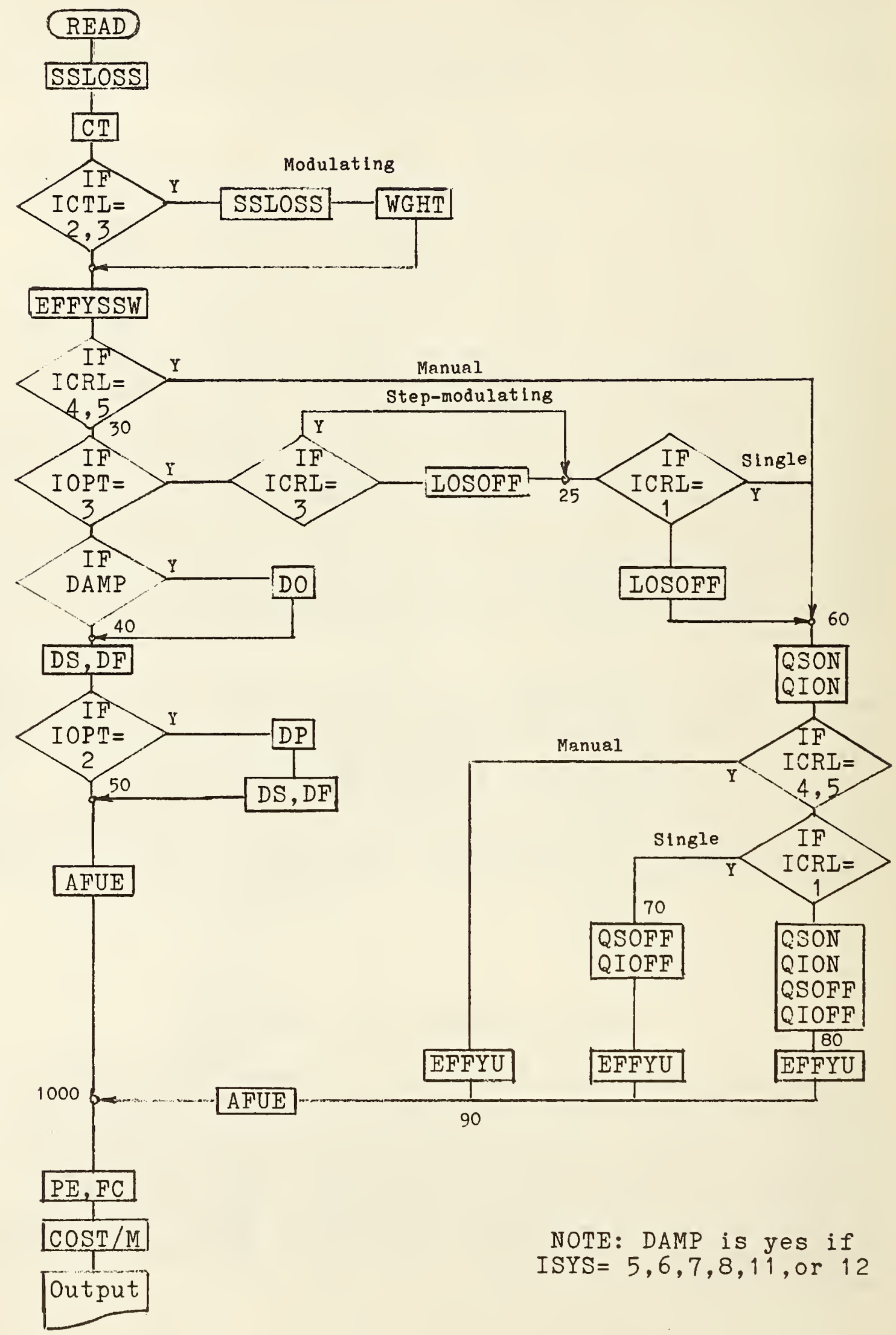

FIGURE 3 
4.1 .3 - The off-cycle stack draft factors, Ds, from Table 1 of the test procedure are not given for systems 9 through 12. For these types, Ds is taken as 1.0, is assigned at line 300 and 2100, and used in line 2410. It would appear that, for direct vent systems, Ds should equal 0.0 .

However, 1.0 was used for $D$ s in the data used in a multiple regression to determine the coefficients of the simplified test method AFUE formula. Because of this, a Ds of 1.0 is used in the program.

4.1 .11 and 4.1 .12 - The heat output rate calculation should include division by 100.0 to change percent to a decimal value. Since these values are used to determine the ratio "R", the omission is not important in the program calculations but the changes were made in lines 3570 and 3590 .

4.1.17 - The simplified test method calculation of AFUE on line 2410 uses 3.93 as the coefficient for the jacket loss, Lj, because this value is a multiple regression coefficient. A change in one coefficient would require a change in the others. The change from 3.93 to 2.8 in the test procedure was made to reduce the adjustment factor for lower outdoor air temperature and cycling conditions. Measured jacket loss may be multiplied by 0.7 prior to entering the data and running the program to make the test procedure allowed reduction. However, the correlation between results obtained using the simplified vs. the standard test methods is not known.

4.2 .1 - The ratio of $S / F$ is not given in a table or calculated for units using outside air for combustion or for oil fueled units. This S/F calculation and the section 4.2 .2 calculation of "Ki, on" are used for all types of units in later section 4.3. The program has been written to use 0.0 for $\mathrm{S} / \mathrm{F}$ for outside installations. The 0.0 causes "Li, on" to be calculated as zero for floor furnaces. The subroutine SSLOSS has been written so that for oil fueled units, a ratio of Rt,s to Rt, $f$ is used without the 1.3 multiplication factor if a $\mathrm{CO} 2$ measurement was made in the stack (above the barometric damper). If not measured, a $\mathrm{S} / \mathrm{F}$ of 1.4 is assigned. The assignments or calculation is made in the subroutine SSLOSS on lines 3870, 3880, and 3930.

4.2 .5 - The psuedo part-load efficiency calculation for manually controlled units omits jacket losses of floor or outside installations. Although none are known to exist, such designs are possible so the program has been modified at Iine 2550 to subtract $C j *$ Lj to calculate this efficiency, EFFYU. In the attached examples, Appendix $C$, the second example showed a AFUE of $12 \%$ lower than if $\mathrm{Cj}=2.8$ and $\mathrm{L} j=4.5$ were omitted.

4.3.2 - The values of X1 and X2 are reversed in the test procedure, section 4.1.2. The correct values are used in lines 2630 and 2670 in the program. 
$4.3 .3,4.3 .5$ and 4.3 .6 - The values of 20 minutes for ton and toff are given in the test procedure. The correct 10 minute value is used in the program on the several lines on which these values appear. Also, the number of measured values of tracer gas concentration and flue gas temperature is ten instead of twenty as listed in the procedure.

4.3.6 - The typographic error in section 4.3 .6 that used "Ls, off" a second time instead of "Li, off" was corrected on line 2850 of the program.

4.3.7 - The weighted steady-state efficiency was used on line 2920 instead of just steady-state efficiency for the calculation of AFUE as was done in section 4.3 .7

4.5.1 The value 100.0 was replaced with the variable CTT on line 2170 so that diluted tracer gas may be used for the "Dp" test as it was permitted in the offloss test on line 3330 of subroutine LOSOFF. The variable was defined in section 4.5 .1 but not used in the equation. 


\section{CONCLUSIONS}

The Fortran program described in this report was tested with many simulated runs with as many combinations of heater types, control types, test options etc. as practical. A few of these tests are included in Appendix C for illustrative purposes.

Each run is preceded by a printout of the data entry file used. The examples are not actual tests but were made up to cover extreme conditions. The Fortran 77 computer program of this report should prove useful to the vented heater manufacturing industry, testing laboratories, and those persons who must understand the test procedure and its calculations. 

$100 \mathrm{C}$ $110 \mathrm{C}$ $120 \mathrm{C}$ $130 \mathrm{C}$ $140 \mathrm{C}$ $150 \mathrm{C}$ $160 \mathrm{C}$ $170 \mathrm{C}$ $180 \mathrm{C}$ $190 \mathrm{C}$ $200 \mathrm{C}$ $210 \mathrm{C}$ $220 \mathrm{C}$ $230 \mathrm{C}$ $240 \mathrm{C}$ $250 \mathrm{C}$

502

\section{HTRS*PROG.VENT *****}

Program to use the DOE test procedure for Vented Heaters on units having single, two-stage, step-modulating or manual controls. The manual type may have adjustable fuel rate or only on-off control. A test method for thermal dampers is also included.

This program is based on the previously published program titled FBVH but is modified to include the changed procedures of the ammended final rule.

Input to the program starts with two lines of identification. The input data to the program requires three additional lines but other lines may be added to provide data for reduced firing rate, damper measurements, and optional power burner draft factor data or off-loss test data.

By: R.A.Wise, F.C.Parsons, 3-1-84
DIMENSION TITLE (20,2), CTO(10), $\operatorname{TFO}(10), \operatorname{CTOR}(10), \operatorname{TFOR}(10)$, \# $\operatorname{CDF}(12), \operatorname{CDS}(12)$

DATA PI/3.141592654/

DATA CDF $/ 1 ., .4,1 ., .4,1 ., .4,1 ., .4,1 ., .4,1 ., .4 /$

DATA CDS $/ 3 * 1 ., .85,4 *-1 ., 4 * 1.0 /$

DATA TOAHI, TON, TOFF/45.,10.,10./

$\operatorname{WRITE}(6,500)$

FORMAT( ( / /2OX, 'VENTED HEATER TEST REPORT')

$\operatorname{WRITE}(6,501)$

FORMAT(/2X,'Input data, type-"@ADD FILENAME.ELEMENTNAME"' )

Read two lines of title and test set-up information.

READ (5,502) TITLE

FORMAT (20A4)

WRITE $(6,503)$ ( (TITLE $(I, J), I=1,20), J=1,2)$

503 FORMAT $(/ 2(5 \mathrm{X}, 20 \mathrm{~A} 4 /))$

Read test conditions

READ (5,*) ISYS, IFUL, ICRL, IOPT , FC, EC

ISYS----

$1=$ Hood/diverter, Atmos.

C $2=$ Hood/diverter, Power

C 3=Barometric, Atmos.

C 4=Barometric, Power

C 5=Hood/Diverter, Atmos., Damp.

C $6=$ Hood/Diverter, Power, Damp.

C - - - IFUL_---

C $1=\mathrm{No} .1$ oil

C $2=N 0.2$ oil

C $3=$ Natural gas

C $4=$ Manufactured

C $5=$ Propane

C $6=$ Butane

$1=$ Single stage

2=Two stage

$3=$ Step Modulating

$4=$ Manual $\mathrm{w} /$ heat control

$5=$ Manual, on - off
$7=$ Barometric, Atmos., Damper

8=Barometric, Power, Damper

$9=$ Direct, Atmos.

$10=$ Direct, Power

$11=$ Direct, Atmos., Damper

$12=$ Direct, Power, Damper

\section{----IOPT}

$1=$ No optional tests $2=$ Meas.draft factor $3=$ Measured off-loss or thermal damper 
$670 \quad 521$

680

690522

700

710

$720 \quad 523$

730

740

$750 \quad 524$

760

$770 \quad 525$

780

790526

800

810

820

830528

840

850

860

870

880

890

900

910

920

930

940

$950 \quad 531$

960

970

980

990

1000

1010

1020

10301

1040

1050

1060

1070532

1080

10904

1100

1110

1120

1130

1140

1150

1160

1170

1180

1190

1200

1210534

1220

12302

1240

1250

533

FORMAT ( $/ 1 \mathrm{X}, 1 * * * * * * * * * * *$ INPUT SELECTIONS WRITE $(6,522)$

FORMAT( $/ 1 \mathrm{X}$, 'SYSTEM \# FUEL CONTROL OPTIONS ', \# 'FUEL-COST ELECT-COST')

WRITE $(6,523)$ ISYS, IFUL, ICRI, IOPT , FC, EC

FORMAT $(4(6 \mathrm{X}, \mathrm{I} 1), 6 \mathrm{X}, 2(3 \mathrm{X}, \mathrm{F} 6.2))$

$\operatorname{READ}(5, *) \mathrm{QP}, \mathrm{PE}, \mathrm{QJ}$

IF ( QP.GT.0.0)WRITE $(6,524) Q P$

FORMAT ( $1 \mathrm{X}$, 'WITH PILOT LIGHT, $Q \mathrm{P}=\mathrm{BTU} / \mathrm{MIN} .=$ ', F5.1)

$\operatorname{IF}(\mathrm{QP} . \mathrm{LT}$. 1.0)WRITE $(6,525)$

FORMAT ( $1 \mathrm{X}$, 'WITHOUT PILOT LIGHT')

WRITE $(6,526) \mathrm{PE}$

FORMAT ( $1 \mathrm{X}$, 'ELECTRIC POWER, KW=', F4.3)

IF (QJ.GT.0.0)WRITE $(6,527)$ QJ

527 FORMAT ( $1 \mathrm{X}$, 'JACKET LOSS, \% LOSS=', F5.2, / )

IF (QJ.LT . 1.0)WRITE $(6,528)$

FORMAT ( $1 \mathrm{X}$, ' INSTALLED INDOORS', /)

WRITE $(6, *)+* * * * * * * * * * *$ INPUT DATA

IF(ICRL.NE.4)WRITE $(6, *)$ 'HIGH FUEL INPUT RATE DATA'

IF (ICRL.EQ.4)WRITE ( $6, *)$ ' 50\% FUEL INPUT RATE'

$\operatorname{WRITE}(6,530)$

FORMAT ( $5 \mathrm{X}$, 'INPUT

\# / 4 X, ' BTU/MIN

$\begin{array}{llcll}\text { AMB } & \text { TEMP } & \text { TEMP } & \text { C02 } & \text { CO2' }^{\prime} \\ \text { TEMP } & \text { STACK } & \text { FLUE } & \text { STACK } & \text { FLUE') }\end{array}$

$\operatorname{READ}(5, *) \mathrm{QIN}, \mathrm{TRA}, \mathrm{TSS}, \mathrm{TFS}, \mathrm{CO} 2 \mathrm{~S}, \mathrm{CO} 2 \mathrm{~F}$

IF (TRA. LT . 40.0. AND. TSS. GT . 10.0) TSS $=C F(T S S)$

IF (TRA . LT . 40.0. AND. TFS. GT . 10.0) TFS $=C F(T F S)$

IF (TRA. LT . 40.0) TRA =CF (TRA)

WRITE $(6,531)$ QIN, TRA, TSS, TFS, CO2S, CO2F

FORMAT ( $4 \mathrm{X}, 6 \mathrm{~F} 7.1$ )

IF ( ICRL.EQ. 1.OR. ICRL.GT.3)GO TO 1

WRITE $(6, *)$ 'LOW FUEL INPUT RATE'

READ $(5, *)$ QINR, TRAR, TSSR, TFSR, C02SR, C02FR

IF (TRAR . IT . 40.0. AND.TSSR . GT . 10.0) TSSR=CF (TSSR)

IF (TRAR . IT . 40.0.AND. TFSR. GT . 10.0) TFSR=CF (TFSR)

IF (TRAR.IT . 40.0) TRAR=CF (TRAR)

WRITE $(6,531)$ QINR, TRAR, TSSR, TFSR, C02SR, C02FR

IF ( IOPT.EQ.3)GO TO 2

IF (ISYS.LT.5.OR. (ISYS.GT.8.AND. ISYS.LT.11))GO TO 4

$\operatorname{READ}(5, *) A D, A S, A N$

WRITE $(6,532) \mathrm{AD}, \mathrm{AS}, \mathrm{AN}$

532 FORMAT (' DAMPER MEASUREMENTS: DAMPER AREA=',F6.2, \# , STACK AREA =', F6.2,' ANGLE=', F4.1)

IF (IOPT.NE. 2)GO TO 5

WRITE $(6, *)$ ' OPTIONAL Dp PROCEDURE TEST DATA' WRITE $(6,533)$

FORMAT ( $1 \mathrm{X}, 1$

TEMP. CONC. VOIM.

\# $/ 1 X, 1$ PRES. TRAC. TRAC. TRAC.

CONC. FLUE

TEMP.', $\operatorname{READ}(5, *) \mathrm{PB}, \mathrm{TT}, \mathrm{CTT}, \mathrm{VT}, \mathrm{CT}, \mathrm{TF}$

$\mathrm{IF}(\mathrm{PB} \cdot \mathrm{EQ} \cdot 0.0) \mathrm{PB}=30.0$

$\mathrm{IF}(\mathrm{PB} . \mathrm{GT} .100.) \mathrm{PB}=\mathrm{PB} / 33.867$

$\mathrm{IF}(\mathrm{TT} \cdot \mathrm{EQ} \cdot 0.0) \mathrm{TT}=\mathrm{TRA}$

$\mathrm{IF}(\mathrm{TT} \cdot \mathrm{LT} \cdot 40.0) \mathrm{TF}=\mathrm{CF}(\mathrm{TF})$

$\mathrm{IF}(\mathrm{TT} \cdot \mathrm{IT} \cdot 40.0) \mathrm{TT}=\mathrm{CF}(\mathrm{TT})$

WRITE $(6,534)$ PB, TT, CTT, VT, CT, TF

FORMAT (2X, F5.2, 3X, F4.1, 3(2X, E7.2), 2X, F5.1)

GO TO 5

IF (ICRL.EQ.3)GO TO 3

WRITE $(6, *)$ 'HIGH FIRE OFF-LOSS DATA.'

WRITE $(6,533)$ 
$\operatorname{READ}(5, *)$ PBO, TTO, СTTO, VTO

IF (PBO.EQ . O.0) PBO $=30.0$

IF ( PBO.GT.100.) PBO=PBO/33.867

IF (TTO.EQ.0.0) TTO=TRA

$\operatorname{READ}(5, *)(\operatorname{CTO}(\mathrm{I}), \operatorname{TFO}(\mathrm{I}), \mathrm{I}=1,10)$

IF(TTO.IT.40.0) THEN

DO $22 \quad I=1,10$

ENDIF

IF (TTO. IT . 40.0) TTO $=\mathrm{CF}($ TTO )

WRITE $(6,535)$ ( CTO (I), TFO $(I), I=2,10)$

535 FORMAT (34X, E7.2, 2X, F5.1)

3 IF(ICRI.EQ.1.OR.ICRL.GT.3)GO TO 5

WRITE $(6, *)$ 'LOW FIRE OFF-IOSS DATA.'

IF (ICRL.EQ.3)WRITE $(6,533)$

$\operatorname{READ}(5, *)$ PBOR, TTOR, CTTOR, VTOR

IF ( PBOR . EQ . O.0) PBOR $=30.0$

IF (PBOR.GT.100.) PBOR=PBOR/ 33.867

IF (TTOR.EQ.0.0) TTOR=TRAR

$\operatorname{READ}(5, *)(\operatorname{CTOR}(\mathrm{I}), \operatorname{TFOR}(\mathrm{I}), \mathrm{I}=1,10)$

IF (TTOR.IT. 40.0) THEN

DO $33 \quad I=1,10$

CALI SSLOSS (IFUL, QJ, TRA, TSS, TFS, CO2S, CO2F,

\# HHV , AFRH, QLH, RTFH, QSSH, EFYSSH, SFRH )

$\mathrm{PF}=\mathrm{QP} / \mathrm{QIN}$

$\mathrm{CJ}=0.0$

ENDIF

IF (TTOR.IT . 40.0) TTOR=CF (TTOR)

WRITE $(6,534)$ PBOR, TTOR, CTTOR, VTOR, CTOR ( 1), TFOR (1)

WRITE $(6,535)$ ( CTOR (I), TFOR ( I ), I=2, 10)

CONTINUE

Calculate steady-state values

If outdoor, assign CJ

IF (QJ.GT.1.O) CJ=2.8

Calculate reduced firing rate values.

IF (ICRI.EQ.1.OR.ICRL.GT.3) GO TO 10

CALI SSLOSS (IFUL, QJ, TRAR, TSSR, TFSR, CO2SR, CO2FR,

\# HHV, AFR, QL , RTFM, QSSM, EFYSSM, SFRM )

CALI WGHT ( QIN, EFYSSH, QINR, EFYSSM,

\# RLOW, TOALO, TOAHI, TC)

$\mathrm{RHIGH}=1 .-\mathrm{RLOW}$

WRITE $(6,540)$ RLOW, RHIGH, TC

FORMAT( $/ 3 X$, 'LOW HEAT FRACTION=', F5.3, 3X, 'HIGH HEAT FRACTION $=$ ',

\# F5.3, /3X, 'BALANCE POINT TEMP. $=$ ', F5.2)

Weighted steady-state efficiency calculations.

EFYSSW $=$ EFYSSH

IF (ICRI .EQ. 1 .OR. ICRL .GT. 3)GO TO 20

EFYSSA $=$ EFYSSH

IF ( ICRL.EQ.3) EFYSSA = (EFYSSH-EFYSSM $) *(T C-T O A H I) /(T C-15)+.E F Y S S H$ EFYSSW $=$ RLOW*EFYSSM+RHIGH*EFYSSA 
$1850 \mathrm{C}$

$1860 \mathrm{C}$

187020

1880

1890

1900

1910

1920

193025

1940

1950

$1960 \mathrm{C}$

1970 C

1980 C

199030

2000

2010

2020

2030

2040555

2050 C

$2060 \mathrm{C}$

2070 C

208040

2090

2100

2110

2120

$2130 \mathrm{C}$

$2140 \mathrm{C}$

$2150 \mathrm{C}$

2160

2170

2180

2190

2200

2210

2220

2230

2240

2250

2260

2270

2280

2290

2300

2310

232050

$2330 \mathrm{C}$

$2340 \mathrm{C}$

$2350 \mathrm{C}$

2360 C

2370

2380

2390

2400560

2410

2420

2430 C

Optional tracer gas off-loss calculations.

IF (ICRL.GT.3.)GO TO 60

IF (IOPT .NE. 3) GO TO 30

IF (ICRL .EQ. 3) GO TO 25

CALI LOSOFF( PBO, TTO, CTTO, VTO, CTO, TFO, TON, QIN, TRA, TOAHI, \# QSOFFH, QIOFFH)

IF (ICRL.EQ.1) GO TO 60

CALI LOSOFF ( PBOR, TTOR, CTTOR, VTOR, CTOR, TFOR, TON, QINR, TRAR, TOALO, \# QSOFFM, QIOFFM)

GO TO 60

Calculate electro-mechanical damper factor.

IF (ISYS.LT.5.OR. (ISYS.GT.8.AND.ISYS.IT.11))GO TO 40

$\mathrm{DO}=1.62 *(1 .-\mathrm{AD} * \mathrm{COS}(\mathrm{PI} * \mathrm{AN} / 180.) / \mathrm{AS})$

IF (DO.GT.1.0) DO $=1.0$

IF (DO.LT.0.0) DO $=0.0$

WRITE $(6,555)$ AS, AD, AN, DO

FORMAT ( $\left./ 2 \mathrm{X},{ }^{\prime} \mathrm{As}={ }^{\prime}, \mathrm{F} 5.2,3 \mathrm{X},{ }^{\prime} \mathrm{Ad}={ }^{\prime}, \mathrm{F} 5.2,3 \mathrm{X},{ }^{\prime} \mathrm{A} \mathrm{n}={ }^{\prime}, \mathrm{F} 4.1,3 \mathrm{X},{ }^{\prime} \mathrm{Do}={ }^{\prime}, \mathrm{F} 4.2\right)$

ASSIGN TABLE VALUES FOR DF AND DS

$\mathrm{DF}=\mathrm{CDF}($ ISYS $)$

IF( ISYS .GT 10) DF=DF*DO

$\mathrm{DS}=\mathrm{CDS}($ ISYS $)$

$\operatorname{IF}(\mathrm{DS} \cdot \mathrm{IT} \cdot \mathrm{O} \cdot) \mathrm{DS}=\mathrm{DO}$

IF (ISYS $\cdot E Q \cdot 8) D S=D O * D F$

OPTIONAL PROCEDURE FOR CALCULATING DP,DS AND DF

IF (IOPT.NE.2) GO TO 50

$\mathrm{ZOFF}=1.325 * \mathrm{~PB} * \mathrm{VT} *(\mathrm{CTT}-\mathrm{CT}) /(\mathrm{CT} *(\mathrm{TT}+460)$.

$\mathrm{ZFSS}=\mathrm{ZOFF}$

IF (IFUL.GT . 2) ZFSS $=Z O F F *((T F S-T R A) /(T F-T R A)) * * .56$

$\# *((T F+460) /.(T F S+460)) * *$.

$\mathrm{ZSS}=\mathrm{QIN} *(\mathrm{RTFH} * \mathrm{AFR}+1.) / \mathrm{HHV}$

$\mathrm{DP}=\mathrm{ZFSS} / \mathrm{ZSS}$

$\mathrm{DF}=\mathrm{DP}$

IF (ISYS . GT . 10) DF=DP*DO

IF(ISYS .GT. 8)GO TO 50

IF (ISYS .LT. 3) DS $=1$.

IF (ISYS .EQ. $3.0 R$. ISYS.$E Q \cdot 4) D S=(D P+.79) / 1.4$

IF (ISYS .EQ. $5 \cdot 0 R$. ISYS.$E Q \cdot 6) D S=D O$

IF (ISYS .GT. 6 .AND. (DO*SFRH . LT . 1.)) DS=DP*DO

IF (ISYS .GT. 6 .AND. (DO*SFRH .GE. 1.)) DS $=D P * D O+(.85-D P * D O) *$ \# $(\mathrm{DO}$ * SFRH -1.$) /(\mathrm{SFRH}-1$.

CONTINUE

Calculate AFUE, no thermal damper or off-loss measure and not manual controls.

$I F(D F \cdot G T \cdot 1 \cdot 0) D F=1 \cdot 0$

$I F(D S . G T \cdot 1.0) D S=1.0$

WRITE $(6,560)$ DF, DS

FORMAT ( $\left./ 2 \mathrm{X},{ }^{\prime} \mathrm{Df}={ }^{\prime}, \mathrm{F} 4.2,3 \mathrm{X}, \mathrm{C}^{\prime} \mathrm{Ds}=\mathbf{\prime}^{\prime}, \mathrm{F} 4.2\right)$

$\mathrm{AFUE}=.968 * \mathrm{EFYSSW}-1.78 * \mathrm{DF}-1.89 * \mathrm{DS}-129 . \mathrm{PF}-3.93 * \mathrm{QJ}+1.81$

GO TO 1000 
2440 C Continue calculations for manual control, thermal

damper, or measured off-losses.

Calculate on-cycle losses.

$60 \quad \mathrm{QSON}=\mathrm{QSSH}$

CIONH $=100 . * 24 * \mathrm{SFRH}^{*} \cdot 7^{*}(1 .+\mathrm{RTFH} * \mathrm{AFR}) / \mathrm{HHV}$

QION=CIONH*(70.-45.)

IF(ICRI.EQ.1) GO TO 70

IF (ICRL.GT.3) THEN

Calculate psudo cycling loss for manual controls.

EFFYU $=$ EFYSSW-QION

WRITE $(6,570)$ QION

FORMAT ( $/ 2 \mathrm{X},{ }^{\prime} \mathrm{Ii}$, on $\left.=1, \mathrm{~F} 5.2\right)$

GO TO 90

ENDIF

C Calculate for two stage or modulating controls.

QSSA $=$ QSSH

IF (ICRI.EQ.3) QSSA $=($ QSSH-QSSM $) *(T C-T O A H I) /(T C-15 \cdot)+Q S S M$

$\mathrm{QSON}=\mathrm{RLOW} * \mathrm{QSSM}+\mathrm{RHIGH} * \mathrm{QSSA}$

CIONM $=100 * * 24^{*}$ SFRM $^{*} \cdot 7^{*}\left(1 .+\right.$ RTFM $\left.^{*} \mathrm{AFR}\right) / \mathrm{HHV}$

CIONA $=$ CIONH

IF (ICRI.EQ.3) CIONA $=(C I O N H+C I O N M) / 2$.

QION=RLOW*CIONM* (70.-TOALO)+RHIGH*CIONA*(70.-TOAHI)

Calculate off-cycle losses.

For two stage controls.

$\mathrm{QSOFF}=\mathrm{RLOW} \mathrm{W}^{*} \mathrm{QSOFFM}$

QIOFF $=R I O W^{*} Q I O F F M$

IF( ICRI . EQ. 3) GO TO 80

C For step modulating controls.

$\mathrm{QSOFF}=\mathrm{QSOFF}+\mathrm{RHIGH} * \mathrm{QSOFFH}$

$\mathrm{QIOFF}=\mathrm{QIOFF}+\mathrm{RHIGH} * \mathrm{QIOFFH}$

GO TO 80

C For single stage controls.

70 QSOFF $=$ QSOFFH

$\mathrm{QIOFF}=\mathrm{QIOFFH}$

Calculate cycling, part-load, efficiency.

80

$80 \quad E F F Y U=100 .-Q I-C J * Q J-T O N *(Q S O N+Q S O F F+Q I O N+Q I O F F) /(T O N+P F * T O F F)$

WRITE $(6,580)$ QSON, QION, QSOFF, QIOFF

580 FORMAT (3X, 'Ls, on $=$ ', F5.2, 6X' ' $I$ i, on $=1$, F5.2,

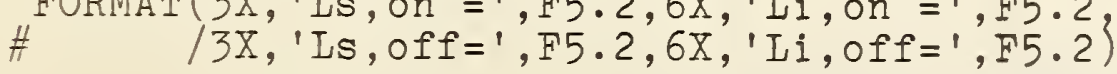

$\mathrm{C}$

C Calculate AFUE.

$90 \quad I F(I C R L . E Q .4) \quad Q I N=Q I N * 2.0$

AFUE $=4400 . *$ EFYSSW*EFFYU*QIN $/(4400 . * E F Y S S W * Q I N+$ $\# 2.5 * 4600$. $* E F F Y * Q P$ )

\section{C}

Calculate electric power.

IF (ICRI.EQ.1.OR.ICRI.GT.3)GO TO 1010

$\mathrm{PE}=\mathrm{PE} * 1 \cdot 3$

IF (ICRI.EQ.2)GO TO 1010

$\mathrm{FR}=\mathrm{QIN} / \mathrm{QINR}$

$\mathrm{PE}=\mathrm{PE} * 1.7$

$I F(F R \cdot G E \cdot 0.7) P E=P E * 1.4$ 


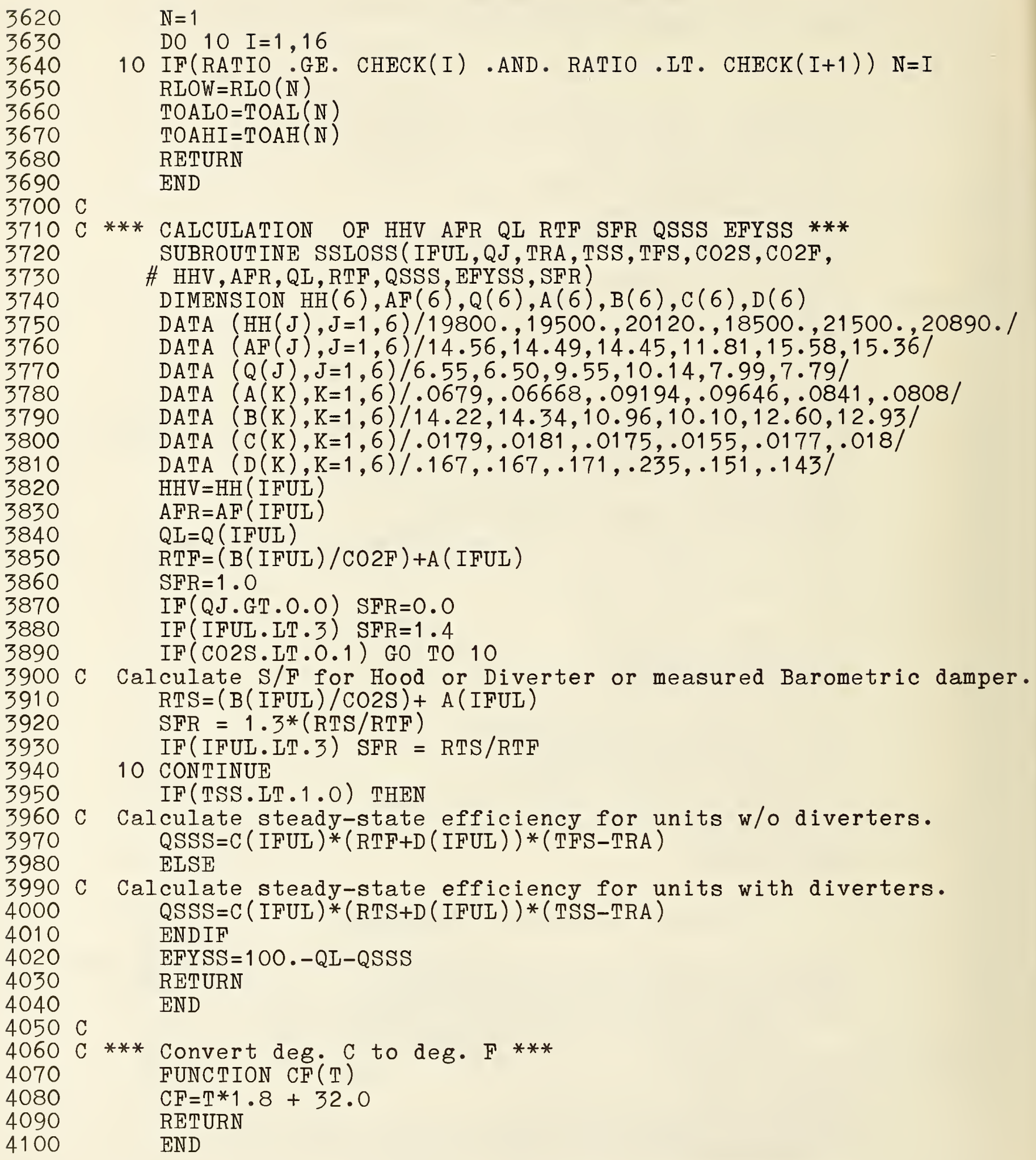


APPENDIX B

DOE TEST PROCEDURE

FEDERAL REGISTER

MARCH 28,1984

Sections pertaining to vented heatersPages 12156, 12157, and 12169 to 12178

Text and equations have been rearranged to be in continuous columns. 



\section{PART 430-ENERGY CONSERVATION PROGRAM FOR CONSUMER PRODUCTS}

Provisions of 10 CFR Part $430 . \S 430.2$. 430.22 Appendix G, Appendix $N$, and Appendix $O$ are anended as follows: (o) Vented home heoting equipment.

(1) The annual fuel utilization cfficiency for veated home heating equinment, expressed in percent, which. is the ratio of the annual fuel output of us eful energy delivered to the heated space to the annual fuel energy input to the vented heater. shall be determined either according to section 4.1 .17 of Appendix $O$ of this subpart for vented heaters without either manual controls or thermal stack dampers: according to section 4.2.6 of Appencix $O$ of this subpart for vented heaters equipped with manual controls: or according to rection 4.3.7 of Appendix $O$ of this subourt for vented beaters equipped with therma! stack dampors.

(2) The estimated operating cost per miilion Btu output for rented heaters without an auxiliary, itric system shall be the product of: (i) One hundred: (ii) the quatient of one million Btu output diviced by the azrual fuel utilization efficiency as de!ernined in paragraph (o) (1) and (iii) the representative unit cost in dollars per Btu for natural gas. propane. or oil, as appropriate, as provided pursuant to section 323(b)(2) of the Act. the resul:ir. product shall be rounded to the nearest 0.01 dollar per million Btu output.

(3) The estimated opcrating cost per million Btu output for $g$ as or oil vented home heating equipment with an auxiliary electric system shall be the product of: (A) The quotient of one million Btu divided by the sum of: (1) The product of the maximum fuel input in Btu's per hour as determined in 3.1.1 or 3.1.2 of Appendix 0 of this subpart times the annual fuel utilization efficiency in percent as determined in 4.1.17, 4.2.6. or 4.3.7 of this appendix as appropriate divided by 100 , plus (2) the product of the maximum electric power in watts as determined in 3.1 .3 of Appendix 0 of this subpart times the quantity 3.412: and (B) of the sum of: (1) the product of the maximum fuel input in Btu's per hour as determined in 3.1.1 of this appendix times the representative urit cost in dollars per Btu for natural 8as. propane, or oil, as appropriate. es provided pursuant to section $323(b)(2)$ of the Act: plus (2) the product of the maximum auxiliary electric power in kilowatts as determined in 3.1.3 of Appendix $O$ of this subpart times the representative unit cost in dollars per kilowatt-hour as provided pursuant to section 323 (b)(2) of the Act the resulting quantity shall be rounded off to the nearest 0.01 dollar per rillion Btu output.

(4) Other useful measures of energy consumption for vented howe heating equipmeat shall be those measures of energy consumption which the Secretary determines are likely to assist consumers in making purchasing decisions and which are derived from the application of Appendix $O$ of this subpart 
5. Appendix O to Subpart B of P.irt 430 is revised to read as follows:

Appendix O to Subpart B of Part 430Criform Test Method for Measuring the Energy Consumption of Vented Home Heating Equipment

1.0 Definitions.

1.1 "Air shitier" mears an adjustable devict: for varying the size of the primary air inlet(s; to the combustion chember power burner.

1.2 "Air tube" means a tube which carries conibustion air from the burner fan to the burner nozzle for combustion.

2.3 "Earometic draft regulator or barometric damper" means a mechanical device designed to maintain a constant draft in a venied heater.

1.4 "Draft hood" means an external device which performs the same function as an integral draft diverter, as defined in section 1.27 of this appendix.

1.5 "Electro-mechanical stack damper" means a type of stack damper which is cperatcd by e!ectrical and/or mechanical means.

1.6 "Excess air" means air which passes through the combustion chamber and the vented heater flues in excess of that which is theoretically required for complete combustion.

1.7 "Flue" means a conduit between the flue outlet of a vented heater and the integral draft diverter, draft hood, barometric damper or vent terminal through which the flue gases pass pror to the poin: of draft relief.

1.8 "Flue damper" means a device installed between the furnace and the integsal draft diverter. draft hood, berometric draft regulator, or vent terminal which is not equipped with a draft control device. designed to open the venting system when the appiiance is in operation and to close the venting sy'stem when the appliance is in a standby condition.

1.9 "Flue gases" means reaction products resulting from the combustion of a fuel with the oxygen of the air, including the inerts and any excess air.

1.10 "Flue losses" means the sum of sensible and latent heat losses above room temperature of the flue gases leaving a vented heater.

1.11 "Flue outlet" means the opening provided in a vented heater for the exhaust of the flue gaves from the combustion chamber.

1.12 "Heat input" $\left(Q_{i n}\right)$ means the rate of energy supplied in a fuel to a vented heater operating under steady-state conditions. expressed in Btu's per hour. It includes any input energy to the pilot light and is obtained by multiplying the measured rate of fuel consumption by the measured higher heating value of the fuel.

1.13 "Heating capacity" $\left(Q_{\text {ove }}\right)$ means the raie of useful heat output from a vented heater, operating under sieady-state conditions, expressed in Btu's per hour. For room and wall heaters, it is obtained by multiplying the "feat input" $\left(Q_{n}\right)$ by the sleady-state efficency $\left(\eta_{\mathrm{wa}}\right)$ divided by 100 . For floor furnaces, it is obtained by multiplying $(A)$ the "heat input" $\left(Q_{1 n}\right)$ by $(B)$ the steady-state efficiency divided by 100. minus the quantity $(2.8)\left(L_{1}\right)$ divided by 100 . where $L$ is the jachet loss as determined in section 3.2 of this appendix.

1.14 "Higher heating value" (HHV) means the heat produced per unit of fuel when complete combustion takes place at constant pressure and the products of combustion ure cooled to the initial temperature of the fucl and air and when the water vapor formed during combustion is condensed. The higher heating value is usually expressed in Btu's per pound, Btu's per cubic foot for gaseous fuel, or Btu's per gallon for liquid fuel.

1.15 "Induced draft" means a method of drawing air into the combustion chamber by mechanical means.

1.16 "Infiltration parameter" means that portion of unconditioned outside air drawn into the heated space as a consequence of loss of conditioned air through the exhaust system of a vented heater.

1.17 "Integral draft diverter" means a device which is an integral part of a vented heater. designed to: (1) Provide for the exhaust of the products of combustion in the event of no draft, back draft, or steppage beyond the draft diverter, 2 j prevent a back draft from entering the vented ieater, and (3) neutralize the stack action of the chimney or $g$ as vent upon the operation of the vented heater.

1.18 "Manually controlled vented heaters" means either gas or oil fueled vented heaters equipped without thermostats:

1.19 "Modulating control" means either a step-modulating or two-stage control.

120 "Power burner" means a venied

heater burner which supplies air for combustion at a pressure exceedir:8 a tunospheric pressure. or a burner which depends on the draft induced by a fan incorporated in the furnace for proper operation.

1.21 "Reduced heat input rate" means the factory adjusted lowest reduced heat input rate for vented home heating equipment equipped with either two stage thermostats or step-modulating thermostats.

1.22 "Single stage thermostat" means a thermostat that cycles a bumer at the maximum heat input rate and off.

1.23 "Slack" means the portion of the exhaust sy'stem downstream of the integral draft diverter, draft hood or barometric draft regulator.

$1.2 \mathrm{~A}$ "Stack damper" means a device installed downstream of the integ:al draft diverter, draft hood, or barometric draft regulator, designed to open the venting system when the appliance is in operation and to close off the venting systern when the appliance is in the standby condition.

1.25 "Stack gases" means the flue gases combined with dilution air that enters at the integral draft diverter, draft hood or barometric draft regulator.

1.26 "Steady-state conditions for vented home heating equipment" means equilibrium conditions as indicated by temperature variations of not more than $5^{\circ} \mathrm{P}(2.8 \mathrm{C})$ in the flue gas temperature for units equipped with draft hoods, barometric draft regulators or direct vent systems, in three guccessive reydings taken 15 minutes a part or not more than $3^{\circ} \mathrm{F}(1.7 \mathrm{C})$ in the stack gas temperature for units equipped with integral draft diverters in three successive readings taken 15 minutes apart.
1.27 "Step-modulating control" niedns a control that either cycles off and on at the low input if the heating load is light, or gradually. increases the heat inpul to miet any higher heating load that carnot be net with the low firing rate.

1.28 "Thermal stack damper" means a type of stack damper which is dependent for operation exclusively upon the direct conversion of thermal energy of tie stack gases into movement of the damper plate.

1.29 "Two stage control" means a control that either cycles a bumer at the reduced heat input rate and off or cycles a bumer at the maximum heat input rate and off.

1.30 "Vaporizing-type oil burner" means a device with an oil vaporizing bowl or other receptacle designed to operate by vaporizing liquid fuel oil by the heat of combustion and mixing the vaporized fuel with air.

1.31 "Vent/air intake terminal" means a derice which is located on the outside of a building and is connected 10 a vented heater by a system of conduits. It is composed of an air intake terminal through which the air for combustion is taken from the outside a tmosphere and a vent terminal from which flue $g$ ises are discharged.

1.32 "Vent limiter" means a device which limits the flow of air from the atmospheric diaphragm chamber of a gas pressure regulator to the atmosphere. A vent limiter may be a limiting orifice or other limiting device.

1.33 "Vent pipe" means the passages and conduits in a direct vent system throligh which gases pass from the combustion chamber to the outdoor air.

2.0 Testing conditions.

2.1 Instollation of test unit.

2.1.1 Vented woil furnaces (including dirsct vent systems). Install gas fueled vented wall furnaces for test as specified in sections 2.1.3 and 2.1.4 of ANSI Z21.49-1975. Install gas fueled wall furnaces with direct vent systems for test as described in sections 2.1.3 and 2.1.4 of ANSI Z21.44-1973. Install oil fueled vented wall furnaces as specified in UL-730-1974, section 33. Install oil fueled vented wall furnaces with direct vent systems as specified in UL 730-1974, section 34.

2.1.2 Vented floor fursoces. Install vented floor furnaces for test as specified in sections 35.1 through 35.5 of UL $729-1978$.

2.1.3 Venled room healers. Install in accordance with manufacturer's instructions.

2.2 Flue and slock requirements.

2.2.1 Gos fueled vented home heoling equipment employing integral droft dive.ters and draft hoods (excluding direct vent systems). Attach to, and vertically above the outlet of gas fueled vented home heating equipment employing draft diverters or draft hoods with vertically discharging outlets, a five (5) foot long test stack having a cross sectional area the same size as the craft diverter outlet.

Atiach to the outlet of vented heaters having a horizontally discharging ¿raft diverter or draft hood outlet a 90 degrec elbow, and a five (5) foot long vertical test stack. A horizontal section of pipe may be used on the floor fumiere between the diverter and the elbow if necessary to clear 
any fruming used in the installation. Use the mu1um.um length of pipe possible for this section. Use stack, elbow, and horizontal section ivith same cross sertional area as the viverter outlet.

\subsubsection{Oil fueled vented home heating} equismicat (excluding direct vent systems). Use nue connections for oil fueled vented floo: furnaces as specified in section 35 of UL :29-1976. sections 34.10 through 34.18 of UL $730-1974$ for oil fueled vented wall furnaces and sections 36.2 and 36.3 of UL $896-1973$ for oil fueled vented room heaters.

2.2.3 Direct vent systems. Have the exhuust/air intake system supplied by the mis nufaciurer in place during all tests. Test units in:ended for installation with a variety of vent pife lengths with the minimum length recommended by the manufacturer. Do not connect a heater employing a direct vent system to a chimney or induced draft source. Vent the gaz solely on the provision for venting incorporated in the heater and the verl/air inıake sy.stem supplied with it. 2.3 Fuei supply:

2.31 Nitural gas. For a vented heater Ltilizing notural gas. maintain the gas supply . $v$ i:.e unit under test at a normal inlet test piessure imnediately ahead of all controls at ; 1010 inches water column. Maintain the rogulator outlet pressure at normal test pressure approximately at that recommended hy the m:anufacturer. Use natural gas having a s:ecific gravity of approximately 0.65 and a higher heating value within \pm 5 percent of 1.025 Blu's per standard cubic foot. Determine the actual higher heating value in Btu's per standard cubic foot for the natural gas to be used in the test with an error no greater than one percent.

2.3.2 Propane gas. For a vented heater utilizing propane gas. maintain the gas supply to the unit under tesi at a normal inlet pressure of 11 to 13 inches water column and a specific gravity of approximately 1.53 . Maintain the regulator outlet pressure, on units so equipped. approximately at that recommended by the manufacturer. Use propane having a specific gravity of affroximately 1.53 and a higher heating value within \pm 5 percent of 2.500 Btu's per standard cubic foot. Determine the actual higher heating value in Btu's per standard cubic fout for the propane to be used in the test with an error no greater than one percent.

2.3.3 Other test gas. Use other test gases with characteristics as described in section 2.2. lable VII, of AVSI Standard Z21.11.11974. Use gases with a measured higher heating value within \pm 5 percent of the values specified in the above ANSI standard. Deicrmine the actual higher heating value of the gars used in the test with an error no greater than one percent.

2.3.4 Oil supply. For a vented heater utilizing fuel oil, use No. 1. fuel oil (kerosene) for vaporizing-type burners and either No. 1 or No. 2 fuel oil, as specified by the manufacturer, for mechanical atomizing type burners. Use No. 1 fuel oil with a viscosity meeting the specifications as specified in UL$73(1)-19 ; 4$, section 36.9 . Use test fuel conforming to the specifications given in tables 2 ard 3 of AVSI Standard Z91.1-1972 for No. 1 and No. 2 fuel oil. Measure the higher heating value of the test fuel with an error no greater than one percent.

2.3.5 Electrical supply. For auxiliary electric components of a vented heater. maintain the electrical supply to the test unit within one percent of the nameplite voltage for the entire test cycle. If a voltage range is used for nameplate voltage. maintain the electrical supply within one percsnt of the mid-point of the nameplate voltage range. 2.4 Burner adjustments.

2.4.1 Gos burner adjustments. Adjust the burners of gas fueled vented heaters to their maximum Btu ratings at the test pressure specified in section 2.3 of this appendix. Correct the burner volumetric flow rate $1060^{\circ}$ $F(15.6 \mathrm{C})$ and 30 inches of mercury barometric pressure. set the fuel flow rate to obtain a heat rate of within \pm 2 percent of the hourly Btu rating specified by the manufacturer as measured after 15 minutes of operation starting with all parts of the vented heater at room temperature. Set the primary air shutters in accordance with the manufacturer's recommendations to give a good flame at this adjustment. Do not allow the deposit of carbon during any test specified herein.

If a vent limiting means is provided on a gas pressure regulator, have it in place during all tes!s.

For gas fueled heaters with rodulating controls adjust the controls to operate the heater at the maximum fuel input rate. Set the thermostat control to the maximum setting. Start the heater by turning the safety control valve to the "on" position. In order to prevent modulation of the burger at maximum input. place the thermostat sensing element in a temperature control bath winich is held at a temperature below the maximum set point temperature of the conirol.

For gas fueled heaters with modulating controls adjust the controls to operate the heater at the reduced fuel in.put rate. Set the thermostat control to the minimum setting. Start the heater by turning the safety control valve to the "or" position. If ambient test room temperature is aoove the lowest control set point temperature. initiate burner operation by placing the thermostat sensing element in a temperature control bath that is held at a temperature below the minimum set point temperature of the control.

2.4.2 Oil burner adjustments. Adjust the burners of oil fueled vented heaters to give the $\mathrm{CO}_{2}$ reading recommended by the manufacturer and an hourly Btu input. during the steady-state performance lest described below. which is within \pm 2 percent of the heater manufacturer's specified normal hourly Btu input rating. On units employing a power burner do not allow smoke in the flue to exceed a No. 1 smoke during the steadystate performance test as measured by the procedure in ANSI Standard Z11.182-1965 (R1971) (ASTM D 2156-65 (1970)). If, on units employing a power burner, the smoke in the flue exceeds a No. 1 smohe during the steady. state test. readjust the burner to give a lower smoke reading. and. if necessary a lower $\mathrm{CO}_{2}$ reading. and start all tests over. Maintain the average draft over the fire and in the flue during the steady-state perfornance test at that recommended by the manufacturer within $\$ 0.005$ inches of water gauge. Du not make additional adjustments to the burner during the required series of performance tests. The instruments and measuring apparatus for this test are described in section 6.3 of ANSI standard Z91.1-1972.

\subsection{Circulating air adjustments.}

2.5.1 Forced air vented wall furnaces (including direct vent systems). During tests maintain the air flow through the reater as specified by the manufacturer and operate the vented heater with the outlet air temperature between $80^{\circ} \mathrm{F}$ and $130^{\circ} \mathrm{F}$ above room temperature. If adjustable air discharge registers a re provided, adjust thers so as to provide the maximum possible air restriction. Measure air discharge temperature as specified in section 2.14 of ANSI Z21.19-1975.

25.2 Fan type vented room heaters and

floor furnaces. During tests on ? зл type furnaces and heaters, adjust the a:r fiow through the heater as specified by the manufacturer. If adiustable air discharge registers are provided, adjust them to p:ovide the maximum possibie air restriction.

2.6 Location of temperature meosuring instrumentation.

26.1 Gas fueled vented hume hea!ir.8 equipment (including direst ver: systems). For units employing an in!egral draft diverter. install nine thermocouples, wired in parallcl. in a horizontal plane in the five foot test stack located one foot from the test stack inlet. Equalize the length of all thermocouple leads before paralleling. Locate one thermocouple in the center of the stack.

Locaté eight thermocouples along imaginary lines intersecting at right ang!es in this horizontal plane at points one third and two thirds of the distance between the center of the stack and the stack wall.

For units which employ a direct vent system, locate at least one thernocouple at the center of each flue way exiting the heat exchanger. Provide radiation shields if the thermocouples are exposed to bumer radiation.

For units which employ a draf: hocul o: units which employ a direct vent system which does not significantly preheat the incoming combustion air. insta!l nine thermocouples. wired in parallel, in a horizontal plane located within 12 irches $(304.8 \mathrm{~mm})$ of the heater outlel and upstream of the draft hood on units so equipped. Locate one thermocouple in the center of the pipe and eight thermocouples alcr.g imagınary lines intersecting at right angies in this horizontal plane at points one third and two thirds of the distance beluern the center of the pipe and the pipe wall.

For units which employ direct vent systems that significantly preheat the incoming combustion air. install nine themocouples. wired in parallel. in a plane parallel to and located within 6 inches $(152+\mathrm{mm})$ of the vent/air intake terminal. Enuatize the length of all thermocouple leads before paralleling Locate one thermocouple in the center of the vent pipe and eight thermocouples along imaginary lines intersecling at nght angles In this plane at points one third and two thirds of the distance between the center of the flue pipe and the pipe wall. 
Use bead-type thermocouples having wire size nol areater than No. 24 American Wire Gauge (AWG). If there is a possibility that the thermocouples could receive direct radiation from the fire, instu!l radiation shields or the fire side of the thernocoup?es only ard uosition the shields so that they do not touch the thermocouple junctions.

Instull thermocouples for measuring conditioned warm air temperature as described in ANSI Z21.49-1975, section 2.14. Establish the tempera!ure of the inlet air by means of single No. 24 AWG bead-iype thermocouple. suitably shielded from direct radiation and located in the center of the plane of tach inlet air opening.

2.6.2 Oil fueled vented home heating equipment (including direct vent systems). Install nine thermocouples, wired in parallel and havirg pizual length leads, in a plane perpendicular to the axis of the flue pipe. Locate this plane at the position shown in Figure 34.4 of UL 730-1974, or Figures 35.1 and 35.2 of UL $729-1976$ for a single thermocouple, except that on direct vent systems which significantly preheat the incoming combustion air, it shall be located within 6 inches $(152.5 \mathrm{~mm})$ of the outlet of the vent/air intake terminal. Locate one thermocouple in the center of the flue pipe and eight thermccouples along imaginary lines intersecting at right angles in this plane at points one third and two thirds of the distance between the center of the pipe and pipe wa!l.

Use bead-lype thermocouples having a wire size nat greater than No. $24 \mathrm{AWG}$. If there is a possibility that the thermocouples could receive direct radiation from the fire. install radiation shields $n$ n the fire side of the

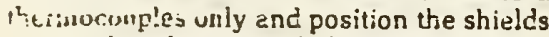
su tinat they do not touch the thermocouple junctions.

Install thermocouples for measuring the ccriditioned warm air temperature as described in sections 35.12 through 35.17 of UL 730-1974. Establish the temperature of the inlel air by means of a single No. 24 AWG bead-type thermocouple. suitably shielded from direct radiation and located in the center of the plane of each inlet air opening. 2.7 Combustion meosurement instrimentotion. Analyze the samples of sid's and Iue gases for vented heaters to delermine the concentration by volume of carbon dioxide present in the dry gas with instrumentation which will result in a reading having an accuracy of \pm 0.1 percentage poinis.

2.8 Ërergy flow instrumentelion. Install one or more irstruments, which measure the rate of gas flow or fuel oil supplied to the vented heater, snd if arpropriate, the electrical energy with an error no greater than one percent.

2.3 Roum anbient temperoture. During the time period required to perform all the testing and measurenient procedures specified in section 3.0 of this appendix. maintain the room temperature within $\pm 5^{\circ} \mathrm{F}$ $( \pm 2.8 C)$ of the value $T_{R A}$ measured during the steady-state periormance test. Ai no time d:uring these tests shall the ruom temperature exceed $100^{\circ} \mathrm{F}(37.8 \mathrm{C})$ or fall below $65^{\circ} \mathrm{F}$ (13.3C).

Temperature $\left(7_{R A}\right)$ shall be the arithmetic average temperature of the test area. determined by rneasurement with four No. 24 AW' $\mathrm{W}$ tead-type thermocouples with junctiors shielued'against radiation. located ap:prox:mateiy at 90-degree positions on a circle circumseriting the heater or heater enciosure under test, in a horizontal plane approxinate!y at ihe vertical midpoint of the appliance or test enclosure, and with the junctions approximately 24 inches from sides of the heater or test enclosure and located so as not to be affected by other than roum air. Locate a thernıcouple at each elevation of draft ralief inlet opening and combustion air inlet opening at a distance of approximately 24 inches from the inlet openings. The temperature of the air for combustion and the air for draft relief shall not differ more than $\pm 5^{\circ} \mathrm{F}$ from room temperature as measured above.

2.10 Equipment used to measure mass flow rate in flue and stock. The tracer gas chosen for this task should have a density which is less than or approximately equal to the density of air. Use a gas unreactive with the environment to be encounte:ed. Using insirumentation of either the batch or continuous type. measure the corcentration of tracer gas with an error no greater than 2 percert of the value of the concentration m.easured.

3.0 Testing and meosuremenis.

3.1 Sieady.state testing.

3.1.1 Gas fueled venied tiume heating equipreat (including oirect ven: sy'stens). Set up the vented heater as specified in sections 2.1, 2.2, and 2.3 of this appendix. The droft diverter shall be in the normal open condition and the stack shall not be insulated. (Insulation of the stack is no longer required for the vented hester test.) Begin the sieady-state perfo:mance test by operating the burier and the circulating air blo:ver, on units so equipped, with the adjustments specified by sections 2.4 .1 and 2.5 of this eppendix, uatil steady-state conditions are st:ained as indicated by a temperature variation of not more than $3^{\circ} \mathrm{F}(1.7 \mathrm{C})$ in the stack gas temperature for vented heaters equipped with draft diverters or $5^{\circ} F(2.8 \mathrm{C})$ in the flue gas temperature for vented heaterg equipped with either draft hoods or direct vert systenis; in three successive readings taken 15 minules apart.

On units employing draft diverters. measure the room temperature $\left(T_{r u}\right)$ as descriter in section 2.9 of this appendix and measure the steady-state stack gas temperature $\left(\mathrm{T}_{\text {s.ss }}\right)$ using the nine thermucouples located in the 5 fout test stack as specified in section 2.6 .1 of this appendix. Secure a sample of the stack gases in the plane where $T_{\text {s.ss }}$ is measured or within 3.5 feet downstream of this plane. Determine the concentrution by volume of carbon dioxide $\left(X_{c o s}\right)$ present in the dry stack gas. If the loca!icn of the gas samplir.g differs from the tempersture measurenient plare, there shall be no air leaks through tile stack between these two locations.

On units employing draft hoods or clirect vent s\%stems, measire the rocm temperatu:e $\left(T_{R A}\right)$ us described in section 2.9 of this appendix and measure the steady-state flue güs temperature $\left(T_{F . s s}\right)$, using the nine thermocouples located in the fue pipe as described in section 2.6 .1 of t?is appendix.
Stcure a sample of the flue gas in the plane of temperature measurement and determitse the concentration by volune of $\mathrm{CO}_{2}\left(X_{1}, \alpha_{1}\right)$ present in dry flive gas. In addition. for units employing draft hoods, secure a sampie of the stick gas in a horizont al plare in the five funt test stuck located one foot from the test stack inlet: and determine the concentration by volume of $\mathrm{CO}_{3}$ ( $X_{\text {Lo:s) }}$ ) present in diy stac:k gas.

Determine the steady-state heat input ratc $\left(Q_{\text {in }}\right)$ including pilot gas by multiplying the measured higher heating value of the test yas by the steady-state gas input rate corrected to standard conditions of $60^{\circ} \mathrm{F}$ and 30 inches of mercury. Use measured values of gas tempercture and pressure at the meter and the barometric pressure to correct the metered gas flow rate to standard conditions.

After the above test measurements have been completed on units employing draft diverters, secure a sample of the flue gases at the exit of the heat exchanger(s) and determine the concentration of $\mathrm{CO}_{2}\left(\mathrm{X}_{\mathrm{crar}}\right)$ present. In obtaining this sample of flue gas. move the sampling probe around or use a sample probe with multiple sempling ports in order to assure that an average value is obtained for the $\mathrm{CO}_{2}$ concentration. For units with multiple heat exchanger outlets. measure the $\mathrm{CO}_{2}$ concentration in a sample from each outlet to obtain the average $\mathrm{CO}_{2}$ concentration for the unit. A manifold (parallel connected sampling tubes) may be used to obtain this sample.

For heaters with sing!e stage thermostat control (wall mounted electric thermostats). detcrmine the steady-state efficiency at the maximum fuel input rate as specified in section 2.4 of this appendix.

For gas fueled vented heaters equipped with either two stage thermostats or stepmodulating thermostais. determins the steady-state efficiency at the meximum fuel input rate, as specified in section 2.4.1 of this appendix. and at the reduced fuel input rate. as specified in section 2.4 .1 of this appendix.

For manually controlled gas fueled venied heaters, with various input rates determine the steady-state efficiency at a fuel input rate that is within \pm 5 percent of 50 percent of the maximum fuel input rate. If the heater is designed to use a control that precludes operation at other than maximum output (single firing rate) determine the sieady state efficiency at the maximum input rate only.

3.1.2 Oil fueled vented home hea:ing equipment (including direct vent sj'stems). Set up and adjust the vented heater as specified in sections 2.1.2.2, and 2.3.4 of this appendix. Begin the steady-state performance lest by operating the burner and the circulating air blower, on units so equipped. with the adjustments specified by sections 2.4.2 and 2.5 of this appendix.until steady. state conditions are attained as indicated by a temperature variation of not more than $5^{\prime} F$ $(2.8 \mathrm{C})$ in the flue gas temperature in theee successive readings taken 15 minutes apart.

Du not allow smoke in the flue. for units equipped with power burners, to exceed a No. 1 smoke during the steady-state performance test as measured by the procedure described in ANSI standard 211.182-1965 (R1971) (ASTM D 2156-0.5 
$\left(\mid y^{-0} 0\right) \mid$ Maintaila the average draft over the lire and in the brecching during the steady. stute performance test at that recominended by the nusufacturer $=0.005$ inches of water giluge.

Measure the room temperature $\left(T_{R A}\right)$ as described in section 2.9 of this appendix and measure the sieady-stute flue gas temperuture ( $T$, ss) using nine thermocouples located in the fue pipe as described in section 2.6 .2 of this appendix. Secure a sample of the fue gas in the plane of temperature measurement and determine the concentration by volume of $\mathrm{CO}_{2}\left(\mathrm{X}_{\mathrm{CO}=\mathrm{p}}\right)$ present in dry lue gas. Measure and record the steady-state heat input rate $\left(Q_{n}\right)$.

For manualiv controlled oil fueled vented heaters, determine the steady-state efficiency it a fuel input rate that is within \pm 5 percent of 50 peicent of the maximum fuel input rate. 3.1.3 Auxiliar Electric Power

Meosurement. Allow the auxiliary electrical system of a gas or oil vented heater to operate for at least five minutes before recording the maximum auxiliary electric nower measurement from the wattmeter. Fecu:d the maximum electric power $\left(P_{E}\right)$ expressed in kilowatts. For vented heaters with modulating controls, the recorded $\left(P_{E}\right)$ shall be maximum measured electric power multiplied by the following factor (R). For two stige controls, $R=1.3$. For step modulating controls, $R=1.4$ when the ratio of minimum to-maximum fuel input is greater than or equal to $0.7, R=1.7$ when the ratio of minimum-to-maximum fuel input is less than 0.7 and greater than or equal to 0.5 , and $R=2.2$ when the ratio of minimum-tomaximum fuel input is less than 0.5 .

3.2 Jocket loss measurement. Conduct a jacket loss test ror vented floor furnaces. Measure the jackel loss $\left(L_{j}\right)$ in accordance with the ANSI standard Z21.48-1976 section 2.12 .

3.3 Meosurement of the off-cycle losses for vented heoters equipped with thermol stack dompers. Install the thermal stack damper according to the manufacturer's instructions. Unless specified otherwise, the thermal stack damper should be at the draft diverler exit collar. Attach a five foot length of bare stack to the outlet of the damper. Install thermocouples as specified in section 2.6.1 of this appendix.

For s'ented heaters equipped with single stage thermostats, measure the off-cycle losses at the maximum fuel input rate. For vented heaters equipped with two stage thermostats, measure the off-cycle losses at the maximum fuel input rate and at the reduced fuel input rate. For vented heaters equipped with step-modulating thermostats. measure the off-cycle losses at the reduced fuel input rate.

Let the vented heater heat up to a steadystate condition. Feed a tracer gas at a constant metered rate into the stack directly above and within one foot above the stack damper. Record tracer gas flow rate and temperature. Measure the tracer gas concentration in the stack at several locations in a horizontal plane through a cross section of the stack at a point sufficiently above the stack damper to ensure that the tracer gas is well mixed in the stack.

Continuously measure the tracer gas concentration and temperature during a 10 minute cuol down period. Shut the buriser off and immediately begin measuring Iracer gds concentration in the stack, stack temperature. room temperalure. and barometric pressure. Record these values as the midpoint of each one-minute interval between burner shut down and ten minutes after burner shut down. Meter respunse time and sampling delay time shall be considered in timing these measurements.

3.4 Measurement of the effectiveness of electra-mechanical stack dampers. For vented heaters equipped with electromechanical stack dampers, measure the cross sectional area of the stack $\left(A_{a}\right)$, the net area of the damper plate $\left(A_{0}\right)$, and the angle that the damper plate makes when closed with a plane perpendicular to the axis of the stack $(\Omega)$. The net area of the damper flate means the area of the dumper plate minus the area of any hules through the damper plate.

3.5 Pilat light m:eosurement. Measure the energy input rate to the pilot light $\left(Q_{p}\right)$ with an error no greater than 3 percent for vented heaters so equipped.

3.6 Optional procedure for determining $D_{p} D_{F}$ and $D_{s}$ for systems for all types of vented heaters. For all types of vented heaters, $D_{\varepsilon} \cdot D_{F}$ and $D_{S}$ can be measured by the following optional cool down test.

Conduct a cool down test by letting the unit heat up until steady-state conditions are reached, as indicated by temperature variation of not more than $5^{\circ} \mathrm{F}\left(2.8^{\circ} \mathrm{C}\right)$ in the flue gas temperature in three successive readings taken 15 minutes apart, and then shutting the unit off with the stack or flue damper controls by-passed or adjusted so that the stack or flue damper remairs open during the restlting cool down period. If a draft wes rnaintaired on oil fueled units in the fue pipe curirg the steady-state performance test described in section 3.1 of this appendix maintein the same draft (within a rarge of -.001 to +.005 inches of water gauge of the average steady-state draft) during this cool down period.

Measure the Ine gas mass flow rate ( $\mathrm{m}_{P, \mathrm{OFF}}$ ) during the cool down test described above at a specific off-period flue gas temperature and corrected to obtain its value at the steady-state fiue gas temperature $\left(T_{F . S S}\right)$, using the procecure described below.

Within one minute after the unit is shut off to start the cool down test for determining $D_{p}$ begin feeding a tracer gas into the combistion chamber at a constant flow rate of $V_{T}$, and at a point which will al!ow for the best possible mixing with the air flowing through the chamber. (On units equipped with an oil fired power burner, the best location for injecting this tracer gas appears to be through a hole drilled in the air tube.) Periodically measure the value of $V_{T}$ with an instantaneously reading flow meter having an accuracy of \pm 3 percent of the quantity measured. Maintain $V_{T}$ at less than 1 percent of the air nuw rate through the furnace. If a combustible tracer gas is used, there sliould be a delay period between the time the burner gas is shut off and the time the tracer gis is first injected to prevent ignition of the tracer zas.

Between 5 and 6 minutes after the unit is shut off to starl the cool down test. measure ut the exit of the heat exchanger the average fue gas temperature. $T^{*}$ r.om. At the sane instant the flue gas temperature is measured. ulso measure the percent volumetric concentration of tracer gas $C_{T}$ in the flue gas in the same plane where $T^{*}$. Oblain the concentration of tracer gas usino an instrument which will result in an accuracy of \pm 2 percent in the value of $C_{P}$ measured. If use of a continuous reading type instrument results in a delay time between drawing of a sample and its analy'sis. this delay should be taken into account so that the temperature measurement and the measurement of tracer gas concentration coincide. In addition, determine the temperature of the tracer gas entering the flow meter $\left(T_{T}\right)$ and the barometric pressure $\left(\mathrm{P}_{\mathrm{B}}\right)$

The rate of the flue gas mass fluw through the vented heater and the factors $U_{p}, D_{p}$, and $D_{3}$ are calculated by the equations in sections 4.5.1 through 4.5.3 of this appendix.

\subsection{Calculotions.}

4.1 Annual fuel utilizalion efriciency for gos or ail fueled vented hame heoling equipment equipped witiout monual crntrois ond without thermol slack dompers. The following procedure determines the annual fuel utilization efficiency for gas or oil fueled vented home heating equipment equipped without manual controls and without thermal stack dampers.

4.1.1 System number. Obtain the system number from Table 1 of this appendix.

4.1.2 Off-cycle flue gas draft foctar. Based on the system number, determine the offcycle flue gas draft factor $\left(D_{r}\right)$ from Table 1 of this appendix.

4.1.3 Off-cycle stack gos droft factor. Based on the system number. determine the ofi-cycie stack gas diaft factor $\left(D_{2}\right)$ from Table 1 of this appendix.

4.1.4 Pilat froction. Calculate the pilot fraction $\left(P_{F}\right)$ expressed as a decimal and defined as:

$\mathrm{P}_{\mathrm{F}}=\mathrm{Q}_{\mathrm{P}} / \mathrm{Q}_{\mathrm{I}}$

where:

$\mathrm{Q}_{\mathrm{P}}=$ as détined is $=5$ of this appendix

$Q_{\text {in }}=$ as defined in 3.1 of this appendix at the maximum fuel input rate

4.1.5 Jacket lass for fioor furnoces. Determine the jarket loss $\left(L_{1}\right)$ expressed as a percent and measured in accordance with section 3.2 of this appendix For other vented heaters $L_{1}=0.0$.

4.1.6 Latent heat loss. Bused on the fuel. obtain the latent heat loss $\left(L_{L_{1}}\right)$ from Table 2 of this appendix.

4.1.7 Ratio of cambustior air niass flaw rote to staichiamelric air moss flaw rote Determine the ratio of combustion uir mass now rate to stoichiomętric air mass fuw rate $\left(R_{T, F}\right)$. and defined as:

$R_{\text {T. }}=A+B / X_{\text {cour }}$

where:

$A=u s$ determined from Tuble 2 of this appendix

$B=$ us determined from Table 2 uf this appendix

$X_{L(0)}=$ as defined in 3.1 of this appendix

41.8 Raliu of combusian and reliel air moss flow rate la slaichiomelis air niass flow rote. For vented haters equippod with 
either an integral draft diverter or a drafthood, determine the ratio of combustion and relief air mass now rate to stoichiometric air mass now rate $\left(R_{T . S}\right)$. and defined as:

$$
R_{T s}=A+\left[3 / X_{C O, s}\right]
$$

where:

$A=$ as determined from Table 2 of this appendix

$B=$ as determined from Table 2 of this appendix

$\mathrm{X}_{\text {coss }}=$ as defined in 3.1 of this appendix

4.1.9 Sensible heat lass at steady'state aperution. For vented heaters equipped with either an integral draft diverter or a draft hood, determine the sensible heat loss at steady-state operation ( $L_{s . s 5 . A}$ ) expressed as a percent and defined as:

where:

$L_{s . s s . A}=C\left(R_{\text {T.S }}+D\right)\left(T_{s . s s}-T_{R A}\right)$

$\mathrm{C}=\mathrm{as}$ determined from Table 2 of this appendix

$\kappa_{T .5}=a s$ defined in 4.1 .8 of this appendix

$\mathrm{D}=$ as determined from Table 2 of this appendix

$T_{\text {s.ss }}=$ as defined in 3.1 of this appendix

$\mathrm{T}_{\mathrm{BA}}=$ as defined in 2.9 of this appendix

For vented heaters equipped without an integral draft diverter, determine (Ls.ss.A) expressed as a percert and defined as:

$L_{\text {S.S. } . A}=C\left(R_{\text {T. }}+D\right)\left(T_{\text {..55 }}-T_{\text {RAA }}\right)$

where:

$\mathrm{C}=$ as determined from Table 2 of this appendix

$R_{T, F}=2 s$ defined in 4.1.7 of this appendix

$\mathrm{D}=$ as determined from Table 2 of tinis aypendix

$T_{P S S}=$ as defined in 3.1 of this appendix

$\mathrm{T}_{\mathrm{R}}=$ as defined in 2.8 of this appendix

4.1.10 Steady-state efficiency. For vented

lieaters eouipped with single stage

thermostats. calculate the steady-state

efficifncy (excluding jacket loss. $\eta_{\text {is. }}$

expressed in percent and defined as:

iso-100-LLa - Ls.ss.a

where:

$L_{A}=$ as defined in 4.1 .6 of this appendix

Ls.ss.A $_{\text {. as defined in }} \mathbf{4 . 1 . 9}$ of this appendix

For vented heaters equipped with either two stige thermostats or with step-

modulinting themostats. ca!culate the steadystate efficiency at the reduced fuel input rate. $\eta_{\text {s. }}$ L expresised in percent and defined as:

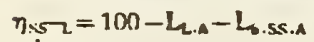

where:

$L_{L_{A}}=$ as delined in 4.1 .6 of this appendix

$L_{\text {S.SS.A }}=a s$ defined in 4.1 .9 of this aprendix in which L..is.A is determined at the reduced fuel input rate

For vented heaters equipped with two stage thermostats. calculate the steady-state efficiency at the maximum fuel input rate. $\eta_{S S} H_{\text {. }}$ expressed in percent and defined as:

$T_{\text {TSS.H }}=100-L_{\text {.A }}-L_{\text {s.s. } . A}$

where:

$L_{L_{-A}}=$ as defined in 4.1 .6 of this appendix

$L_{\text {s.ss. }}=4 \mathrm{~s}$ defined in 4.1 .9 of this appendix in which $L_{\text {s.ss. }}$ is measured at the maximum fuel input rate

For vented heiters equipped with stepinudulating thermostats calculate the weighted-average steady-state efficiency in the modulating mode. $\eta_{5 s}$ mon. . expressed in percent and defined as:

$\eta_{S S \text {. MCU }}=\left[\eta_{S S-11}-\eta_{S S-1}\right]\left[\frac{T_{C}-T_{O A \cdot}}{T_{C}-15}\right]+\eta_{S S L}$

Where:

$\eta_{: S \cdot H}=$ as defined in 4.1 .10 of this appendix $\eta_{\text {SS } L}=$ as defined in 4.1 .10 of this appendix

$\mathrm{T}_{\mathrm{OA}^{*}}=$ average outdonr temperature for rented heaters with step-modulating thermostats operating in the modulating mode and is ohtained from Table 3 or Figure 1 of this appendix

$T_{c}=$ balance point temperature which represen!s a temperature used to apportion the annual heating load between the reduced input cycling mode and either the modulating mode or maximum input cycling mode and is obtained either from Table 3 of this appendix or calculated by the following equation:

$T_{C}=65-[(65-15) R]$

where:

$65=$ average outdoor temperature at which a ven:ed heater starts ope-ating

$15=$ national everage outdooi design temperature for veated heaters

$R=$ ratio of reduced to maximum heat output rates, as def:ned in 4.1 .13 of this appendix

4.1.11 Reduced heat cutput rote. For vented heaters equipped with eitter in'o stage thermostats or step-modulating thermostats. calcuiate the redired heat output rate

(Qred ou:) defined as:

$Q_{\text {red out }}=\eta_{S S \cdot L} Q_{\text {red.in }}$

where:

$\eta_{\mathrm{ss} t}=$ as defined in 4.1 .10 of this appendix

$Q_{\text {red in }}=$ the rediced fuel input rate

4.1.12 Maxinum heat ou!put rate. For vented heaters equipped with either two stage thermostats or step-modulating thermostas. calculate the rraximum heat output rate $\left(Q_{\text {max oul }}\right)$ defined as:

$Q_{\text {mes. out }}-\eta_{\text {ss.h }} Q_{\text {max. In }}$

where:

$\eta_{\mathrm{Sa} \cdot \mathrm{H}}=$ as defined in 4.1.10 of this appendix

$Q_{\max \text { in }}=$ the maximum fuel input rate

4.1.13 Ratio of reduced to maximum heat output rotes. For vented heaters equipped with either two stage thermostals or stepmodulating thermostats, calculate the ratio of reduced to maximum heat output rates (R) expressed as a decimal and defined as:

$R=Q_{\text {red oul }} / Q_{\text {max out }}$

where:

$Q_{\text {red out }}=$ as defined in 4.1 .11 of this appendix $Q_{\text {max aut }}=a 8$ defined in 4.1 .12 of this appendix

4.1.14 Frcction of heating load at reduced operating made. For vented heatters equipped with either two stage thermostats or stepniodulating thermostats, determine the fraction of heating load at the reduced operating mode $\left(X_{1}\right)$ expressed as a decimal and listed in Table 3 of this appendix or obtitined from Figure 2 of this appendix.

4.1.15 Fraction of heating load at maximum aperating mocie ar noncychling morle. For vented heaters equipped with either two stage thermostats or stepmoduluting therostats. determise the fraction of heating load at the maximum operating mode or noncycling mode $\left(X_{2}\right)$ expressed as a decimal and listed in Table 3 of this appendix or obtained from Figure 2 of this appendix.

4.1.16 Weighted-averag'e steady-staie efficiency. For vented heaters equipped with single stage thermostats, the neightedaverage steady-state efficiency $\left(\eta_{55} w_{T}\right)$ is equal to $\eta_{\mathrm{ss}}$. as defined in section 4.1.10 of this appendix. For vented heaters equipped with two stage thermostats. $\eta_{S S}$ as:

$$
\eta_{\text {TSTT }}=\mathrm{X}_{1} \eta_{552}+\mathrm{X}_{2} \eta_{55 T}
$$

where:

$X_{1}=$ as defined in 4.1 .14 of this appendix $\eta_{\mathrm{S}} \mathrm{z}=$ as defined in 4.1 .10 of this appendix $\mathrm{X}_{\mathrm{B}}=$ as defined in 4.1 .15 of this appendix $\eta_{\mathrm{SS}}=$ as defined in 4.1 .10 of this appendix

For vented heaters equipped with stepnodulating thermosta!s. $T_{S S}-w_{T}$ is defined as: $\eta_{S S W T}=X_{1} \eta_{S S Z}+X_{2} \eta_{S S T M O D}$

where:

$X_{2}=$ as defined in 4.1.14 of this appendix $\eta_{\mathrm{SS} z}=$ as defined in 4.1 .10 of this appendix $\mathrm{X}_{2}=$ as defined in 4.1 .15 of this appendix $\eta_{5 S}{ }_{\mathrm{M} D \mathrm{~B}}=$ as defined in $\mathbf{4} 1.10$ of this appendix

4.1.17 Annual fuel uilization efficiency. Calculate the annual fuel titilization efficiency (AFUE) expressed as percent and defined as:

AFUE $=\left[0.968 \eta_{S S T T}\right]-1.78 D-1$

$.89 \mathrm{D}_{\mathrm{s}}-129 \mathrm{P}_{\mathrm{F}}-2.8 \mathrm{~L}_{\mathrm{s}}+1.81$

uhere:

$\eta_{\mathrm{S}} \sim \mathrm{T}_{\mathrm{T}}=$ as defined in 4.1.16 of this appendix $D_{F}=a s$ defined in 4.1.2 of this appendix $D_{s}=a s$ defined in 4.1.3 of this appendix $P_{5}=a s$ defined in 4.1.4 of this appendix $\mathrm{L}_{\mathrm{J}}=$ as defined in 4.1 .5 of this appendix

4.2 Annual fuel utilization efficiency for gas ur ail fueled vented hame heating equipinent equipped with manual cantrals. The following procedure determines the annual fuel utilization efficiency for gas or oil fueled vented home heating equipment equipped with manual controls.

4.2.1 Averoge ratio of slack yas niass flow rute to flue gas mass flaw rote at steady-stute aperation. For vented heaters equipped with either direct vents or direct exhunst or are outdoor units, the average ratio of stack gus mass !ou rate to flue gas mass flow rate at steady-state operation $(S / F)$ shall be equal to unity. $(S / F=1$.) For all other types of vented heaters, calculate $(S / F)$ defined as:

$S / F=1.3 R_{T . S} / R_{T .8}$ 
bitiric

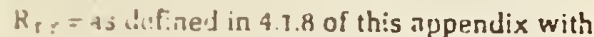

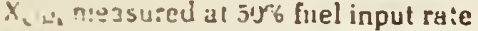
$R_{r . s}=d S$ dufined in 4.1.7 of this appendix with Xos mejs:red at 50"6 fuel input rute

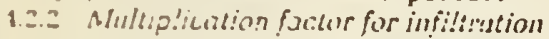
la..s dirring t.uraer an-Cjzle. Calculate the m.lupircdilcial fuctur fur infittration loss durn:; burner on-cycle $\left(K_{\text {s.os }}\right)$ defined as:

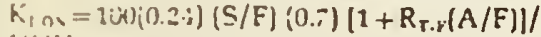
HHW'

inser:

100 = converts a decimal frac:ion intu a precent

0.24 = sptcific heat of dir

$A / F=$ sionch:oretric dir/fuel ratio, do!prmined in accordunce with Table 2 of this arpér. dix

$\mathrm{S} / \mathrm{F}=3 \mathrm{~s}$ itf:red in 4.2 .1 of this appendix at 50 percent of rated maximum fuel input

$0.7=$ infiltration parameter

$R_{r . F}=$ as defined in 4.1.7 of this appendix

$H H V_{A}=$ average higher heating value of the test fuel, determined in accordance with Table 2 of this apperdix

4.2.3 On-cycle infiltration theat loss. Calculute the on-cycle inilltration heat loss $\left(l_{1.0 v}\right)$ expressed us a percent and defined as: $L_{1 .(2),}=K_{1.0 N}(70-15)$

whe:e:

$K_{i, \ldots v}=$ as defined in 4.2 .2 of this appendix

$? 1)=$ average indoor temperature

$4 \bar{j}=$ average outdoor temperature

4.2.1 I!'eighted-Avercae Steady-Siate Eificienr.y. For manus!ly controlled heaters wi'h various input rates the weighted average steady-stute efficiency $\left(\eta_{\mathrm{ss}} \times \mathrm{T}\right)$, is at 50 percent of the maximum fitel input rate as r.ecos'red in either section 3.1.1 to this appenuix for manually controlled gas vented hed:ers cr section 3.1.2 to this appendix for manusliy contrul!ed oil vented heaters. For minitilly controlled heater with one single firing iute the weigh!ed a verage steady-state efficiency is the steady state efficiency meastired ai the sinole firing rate.

4.2.5 Port-lacd fuel utilization efficiency. Calculdte the part-load fuel utilization efficisercy $\left(\eta_{3}\right)$ expressed as a percent and cistived is:

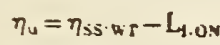

where:

$\eta_{\text {:is }} \cdot \mathrm{T}=$ as defined in 4.2.4 of this appendix $L_{1.0 v}=$ as defined in 4.2 .3 of this appendix

+2.6 Annual fuel utitization efficienry. For manually controlled vented heaters.

Calcula!e the annual fuel utilization

efficiercy (.AFUE) expressed as a percent and defined as:

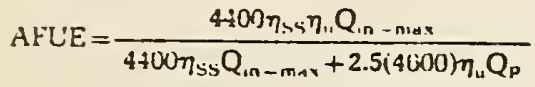

where:

$+1: 0=$ average number of heuting degree days $\eta_{s s}=$ as defilted as $\eta_{s s}$ ut in 4.2.4 of this appendix

$\eta_{\mu}=$ as defined in 4.2 .5 of this appendix

$Q_{\text {in max }}=$ as defised as $Q_{\text {in }}$ at the maximum fue! input rate. as defined in 3.1 of this aวpendix
4600 = average number of non-heuting season. hours per year

$\mathrm{Q}_{0}=$ as defined in 3.5 of this appendix

4.3 Annual fuel utilization efficiency by the tracer gus method. The annual fuel utilization eificiency shall be determined by the following tracer gias method for all vented heaters equipped with thermal stach dampers. All other types of vented heaters can elect to use the folluwing trucer gas method, as an optional procedure.

4.3.1 On-cycle sensible heat loss. For vented heaters equipped with single stage thermostats, calculate the on-cycle sensible heat loss ( $L_{\text {s.on }}$ ) expressed as a percent and defined as:

$L_{\text {B.ON }}=L_{\text {s.ss.A }}$

where:

$L_{\text {s.ss.A }}=$ as defined in 4.1 .9 of this a spendix

For vented heaters equipped with two stage thermostats, calculate $L_{3.0 N}$ defined as:

$L_{\text {s.n. }}=X_{1} L_{\text {S.sS.A.ret }}+X_{2} L_{\text {s.ss.A.man }}$

wheie:

$X_{1}=$ as defined in 4.1.14 of this appendix

$L_{s . s s . A \cdot r e d}=a s$ defired as $L_{s} s s .3$ in $\$ .1 .9$ of this appendix at the reduced fuel input rate

$\mathrm{X}_{2}=$ us defined in 4.1 .15 of this appercix

$L_{\text {s.ss.t. } \max }=$ as defined as $L_{s . s e n}$ in 4.1 .9 of this appendix at the maximum fuel input rate

For vented hecters with step-modulating thermostats, calculate $L_{s . o n}$ defined as:

$L_{\text {s.on }}=X_{1} L_{\text {s.si.A. res }}+X_{2} L_{\text {s.ss.A.eve }}$ where:

$X=1$-as defined in 4.1 .14 of this apperdix

LLS.ss.A.red $=$ as defined in 4.3.1 of this appendix

$X_{2}=$ as defined in 4.1.15 of this appendix

$L_{\text {s.ss.A.avr }}=$ average sensible beat loss for stepmodulating vented heaters operating in the modulating mode

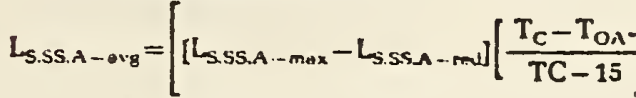

$$
+ \text { Lossis }- \text { md }
$$

where:

$L_{\text {S.ss.A.ave }}=\mathbf{a s}$ defined in 4.3 .1 of this appendix $T_{C}=a s$ defined in $\$ .1 .10$ of this appendix $\mathrm{T}_{\mathrm{OA}} \mathrm{A}^{*}=$ as defined in $\mathbf{4 . 1 . 1 0}$ of this appendix $15=$ as defined in 4.1.10 of this appendix

4.3.2 On-cycle infilt:-ation heat luss. For vented heaters equ:pped with single stage thermostais, calculate the on-cycle infiltration heat loss $\left(\mathcal{L}_{1.0 N}\right)$ expressed as a percent and deñred as:

$L_{1.0 x}=K_{1.0 v}(30-i 5)$

whicre:

$K_{1.0 x}=$ as defined in 4.2.2 of this appendix $70=$ as defined in $\$ .2 .3$ of this append $\mathrm{x}$ $\mathbf{4 5}=$ as defined in $\mathbf{4 . 2 3} \mathrm{ci}$ this appendix

For vented hediers o'iuipped with two stage thermostats, calculdte $L_{1.0 v}$ defined as:

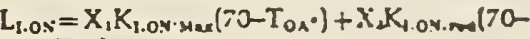
$\left.T_{0 A}\right)$

where:
$X_{t}=a s$ defined in \$.1.14 of this appendix $K_{1.0 N}$ oux $=$ as defined as $K_{1.0 n}$ in $4.2:$ of this appendix at the maximum beat input rate $70=a s$ defined in 4.2.3 of this appendix $\mathrm{T}_{04^{\circ}}=$ as Cefined in 4.3.4 of this appendix $K_{1.0 s \cdot m}=$ as defined as $K_{1.0 \pi}$ in 4.22 of this appendix at the aninimur beat input rate $\mathrm{T}_{2 \lambda}=$ as defined in 4.3 .4 of this appendix $X_{2}=$ as defined in 4.1 .15 of this appendix

For vented heaters equipped with stepmodulistir.8 thermostats, calculate 4 .nv defined as:

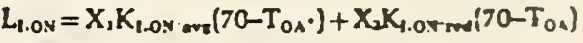
where:

$X_{1}=$ as defined in 4.1.1s of this appendix

$K_{\text {ros.eve }}=\frac{\left|K_{\text {I.On.tran }}+K_{\text {I.On.rod }}\right|}{2}$

$70=2 s$ defined in 4.2.3 of this afpendix $\mathrm{T}_{0 . .^{*}}=$ as defined in 4.3.4 of this apperidix $X_{2}=a s$ defined in $\mathbf{4 . 1 . 1 5}$ of this appendix $\mathrm{T}_{0 \wedge}=$ as defined in 4.3.4 of this appendix

4.3.3 Off-cycle sensible heat loss. Fur vented heaters equipped with single stage thermostats. calculate the off.cyclc sensible heat loss (Ls.orf) at the maximum fuel input rate. For vented heaters equipped with stepmodulating thermostats, calculate $L_{s . n r}$ defined as:

$L_{\text {s. OFF }}=X_{1} L_{\text {s.orr.red }}$

where:

$X_{1}=$ as defined in 4.1 .14 of this appencix $L_{\text {s.ort.red }}=$ as defined as $L_{\text {s.oir }}$ in 4.3 .3 of this

apperidix at the reduced fuel input rate

For vented heaters equipged with two stage thermostals, calculate Lson defined as:

$L_{\text {s.orv }}=X_{1} L_{\text {s.orr.nod }}+X_{2} L_{\text {s.orr.us }}$

where:

$X_{1}=$ as defined in 4.1 .14 of this apperdix

$L_{\text {s. off red }}=$ as defined as $L_{\text {s orr }}$ in 4.3 .3 of this uppendix at the reduced fuel input rate

$X_{2}=$ as defined in 4.1.15 of this appendix

$L_{\text {S.nF.M. }}=$ as defined as $\mathrm{L}_{\text {s.or }}$ in $\mathbf{4 . 3 . 3}$ of this appendix at the maximun fuel inp'st paie

Calculdie tre off-cycle sensibie heat !osg (L.oor) exp:essed as a percent and defined as: 


$$
L_{\text {S.OFF }}=\frac{100(0.24)}{. Q_{\text {in }} t_{\text {un }}} \sum m_{\text {S.OFF }}\left(T_{\text {S.OFF }}-T_{R N}\right.
$$

where:

$100=$ conversion factor for percent

$0.24=$ specific heat of air in Btu per pound - $F$

$Q_{1 n}=$ fuel in put rate, as defined in 3.1 of this appcadix in Btu per minute (as appropriate for the firing ratel

$L_{o n}=a v e r a g e$ burner on-time per cycle and is 20 minutes

$\Sigma m_{\text {s.nFF }}\left(T_{\text {S.OFF }}-T_{R A}\right)=$ summation of the twenty values of the quantity, $m_{\text {s.orr }}\left(T_{S .0}\right.$ FF $-T_{\mathrm{RA}}$ l, measured in accordance with 3.3 of this appendix

$\mathrm{m}_{\mathrm{s.ort}}=$ stack gas mass Ilow rate pounds per minute

$$
\mathrm{m}_{\mathrm{S} . \text { ORF }}=\frac{1.325 \mathrm{P}_{\mathrm{B}} \mathrm{V}_{\mathrm{T}}\left(\mathrm{C}_{\mathrm{T}^{*}}-\mathrm{C}_{\mathrm{T}}\right)}{\mathrm{C}_{\mathrm{T}}\left(\mathrm{T}_{\mathrm{T}}+460\right)}
$$

$T_{\text {S.oF }}=$ stack gas temperature measured in accordance with 3.3 of this appendix

$T_{\mathrm{F}_{4}}=$ average room temperature measured in accordance with 3.3 of this appendix

$P_{B}=$ barometric pressure in inches of mercury

$V_{I}=$ חow rate of the tracer gas through the stack in cubic feet per minute

$C_{\tau}=$ concentration by volume of the active tracer gas in the mixture in percent and is 100 when the tracer gas is a single compuritiat ges

$C_{\tau}=$ concentration by volume of the active tracer gas in the diluted stack gas in percent.

$\mathrm{T}_{\mathrm{r}}=$ temperature of the tracer gas entering the flow meter in degrees Fahrenheit

$\left(T_{T}+460\right)=a b s o l u i e$ temperature of the tracer gas entering the flow meter in degrees Kankine

4.3.4 Average outdaor temperature. For vented heaters equipped with single stage thermostats, the average outdoor temperature $\left(T_{0 .}\right)$ is $45^{\circ} \mathrm{F}$. For vented heaters equipped with either two stage thermostats or stepmodulating thermostats, $\Gamma_{0 \text { o }}$ during the reduced opereting mode is obtained from Taule 3 or Figure 1 of this appendix. For venied heaters equipped with two stage thermostats. $\mathrm{T}_{\mathrm{OA}}$ " during the maximum operating mode is obtained from Table 3 or Figure 1 of this appendix.

4.3.5 Off-cycle infiltration heat lass. For vented heaters equipped with single stage thermostats, calculate the off-cycle infiltration heat loss ( $L_{\text {..urr }}$ ) at the maximum fuel input rate. For vented heaters equipped with step-modulating thermostats, calculate $L_{1,0 r}$ defined as:

$L_{\text {.oFr }}=X_{1} L_{\text {I.UFT. }}$.red

where:

$X_{3}=$ as defined in 4.1.14 of this appendix $L_{\text {i.nFF.red }}=$ as defined in $L_{\text {1.OFr }}$ in 4.3 .3 of this appendix at the reduced fuel input rate

For vented heaters eçuipped with two stage thermostats, calculate $L_{1.0 r r}$ defincd as: $\mathrm{L}_{\text {1.orf }}=X_{1} L_{\text {1.orr.mod }}{ }^{+} X_{2} L_{\text {l.orr.max }}$

where:

$X_{1}=$ as defined in $\mathbf{4} .1 .14$ of this appendix
$L_{1.07 .}$ red $=$ as defined as $L_{1.0 F 5}$ in 4.3 .3 of this appendix at the reduced fuel input rate $X_{2}=$ as defined in 4.1:15 of this appendix

$L_{\text {1.orr.max }}=$ as defined as $L_{1.0 \%}$ in 4.3 .3 of this appendix at the maximum fuel input rate

Calculate the off-cycle infiltration heat loss ( $L_{\text {.or }}$ ) expressed as a percent and defined as:

$$
L_{\text {I.OFF }}=\frac{100(0.24)(1.3)(0.7)\left(70-T_{U A}\right)}{Q_{\text {in }} t_{\text {on }}} \sum m_{\text {S.OFF }}
$$

where:

$100=$ conversion factor for percent

$0.24=$ specific heat of air in Btu per pound $F$

1.3= dimensionless factor for converting laboratory messured stack flow to typical ficld conoitions

$0.7=$ infiltration parameter

$70=$ assumed average indoor air temperature. - $F$

$\mathrm{T}_{\mathrm{OA}}=$ avr.age outdoor temperature as defined ir 4.3.4 of this appendix

$Q_{.}=$fuel input rate, as defined in 3.1 of this appendix in Btu per minute (as appropriate for the firing rate)

$t_{\mathrm{L}}=$ average bumer on-time per cycle and is 20 minutes

$\Sigma m_{\text {S.off }}=$ summation of the twenty values of the ouantity, $\mathrm{m}_{\mathrm{s} . \mathrm{orr}}$, measured in accordance with 3.3 of this appendix

$\mathrm{m}_{\mathrm{S} \text {.ofr }}=$ as defined in 4.3 .3 of this appendix

4.3.6 Part-load fuel utilizatian efficiency.

Calculate the part-load fuel utilization

efficiency $\left(\eta_{u}\right)$ expressed as a percent and defined as :

$$
\begin{aligned}
& \eta_{u}=100-L_{1, A}-C_{j} L_{j}-\left[\frac{t_{0 n}}{t_{o n}+P_{p} t_{\text {OFF }}}\right] \\
& +\left[L_{\text {s.on }}+L_{3 \cdot 0 r}+L_{1 \cdot 0 n}+L_{s \cdot 0 r r}\right]
\end{aligned}
$$

where:

$C,=2.3$. adjustmen: factor

$\mathbf{L},=$ jacket loss as defired in $4 . \overline{2} . \overline{5}$

$L_{L A}=$ as defined in 4.1 .6 of this appendix

$t_{0 n}=2 s$ defined in 4.3 .3 of this appendix

$t_{\text {s.os }}=$ as defined in 4.3 .1 of this appendix

L.0 $=$ as defined in 4.3 .3 of this appendix

$L_{1.05}=$ as defined in 4.3 .2 of this appendix

$L_{1.0 r}=$ as deñned in $4.1 .4 \mathrm{cf}$ this appendix

$\mathrm{P}_{\mathrm{F}}=$ as defined in 4.1.4 of this appendix

$\mathrm{P}_{\mathrm{F}}=\mathrm{average}$ burner off-time per cycle and is 20 minutes

4.3.7 Annual fuel witization efficiency.

Calculate the annual fuel utilization

efficiency (AFUE) expressed as a percent and defined as:

$$
A F U E=\frac{4400 \eta_{s s-w \tau} \eta_{u} Q_{t n-m n d}}{4400 \eta_{s s} Q_{i n-\max }+2.5(4660) \eta_{u} Q_{p}}
$$

where:

$\mathbf{4 4 0 0}=$ as defined in $\mathbf{4 . 2 . 6}$

$\eta_{S-\text { TT }}=$ as defined in 4.1.16 of this appendix $\eta_{4}=$ as defined in 4.3 .6 of this appendix $\mathrm{Q}_{\mathrm{in}-\operatorname{man}}=$ as defined in 4.2 .6 of this appendix $4600=8$ defined in 4.2 .6 of this appendix $Q_{D}=a s$ defined in 3.5 of this appendix
4.4 Stack damper effectiveness for vented heaters equipped with electro-mechanical stack dampers. Determine the stack damper effectivieness for vented heaters equipped with electro-mechanical stack dampers $\left(D_{0}\right)$, defined as:

$D_{0}=1.62\left[1-A_{D} \cos \Omega / A_{S}\right]$

where:

$A_{v}=$ as defined in 3.4 of this uppendix $\mathbf{\Omega}=\mathbf{a s}$ defined in $\mathbf{3 . 4}$ of this appendix $A_{S}=$ as defined in 3.4 of this appendix 4.5 Addition requirements for vented home heating equipment using indoar air for combustion and draft cantral. For vented home heating equipment using indour air for combustion and draft control. $D_{\mathrm{r}}$ as described in section 4.1.2 of this appendix, and $D_{5}$, as described in section 4.1.3 of this appendix, shall be determined from Tab!e 1 of this appendix.

4.5.1 Optianal procedure fo- determining $\mathrm{D}_{\mathrm{p}}$ for vented hame heating equipment. Calculate the ratio $\left(D_{p}\right)$ of the rate of nue gas mass through the vented hea!e: during the off-period, $\mathbf{M}_{\text {r.orr }}\left[T_{F, s s}\right)_{\text {, to the rate of flue ges }}$ mass flow during the on-period, $M_{\text {r.ss }}$ ( $T_{\text {r.ss }}$ ), and defined as:

$D_{P}=M_{F .0 F T}\left(T_{\text {F.SS }}\right) / M_{F . s s}\left(T_{F . s S}\right)$

For vented heaters in which no draft is maintained during the steady-state or cool down testa, $\mathbf{M}_{\mathbf{F} . \text { orf }}\left(\mathbf{T}_{\mathbf{F . s s}}\right)$ is defined as:

$\mathrm{M}_{\mathrm{F} . \mathrm{OHF}}\left(\mathrm{T}_{\mathrm{F} . \mathrm{SS}}\right)=$

$M_{\text {r.OFF }}\left(T^{*}{ }_{\text {F.OFF }}\right)\left[\frac{T_{F . S S}-T_{K A}}{T^{*}{ }_{\text {F.OFF }}-T_{R A}}\right]^{0.5 \theta}\left[\frac{T_{F . O H F}^{*}+460}{T_{F . S S}+450}\right\}^{1}$

For oil fueled vented heaters in which an imposed draft is maintained, as described in section 3.6 of this appendix. $\mathrm{M}_{\mathrm{F} . \mathrm{FF}}\left(\mathrm{T}_{\mathrm{F} . \mathrm{ss}}\right)$ is defined as:

$M_{\text {F.OFT }}\left(T_{\text {F.SS }}\right)=M_{\text {F.OFF }}\left(T^{*}{ }^{*}\right.$.S.S $)$

where:

$T_{\text {F.ss }}=a 3$ defined in 3.1.1 of this appendix $T^{*}$ F.orf $=$ flue gas temperature duing the offperiod measured in accurdance with 3.5 of this appendix in degrees Fahrenheit

$T_{M A}=$ as defined in 2.9 of this appendix 


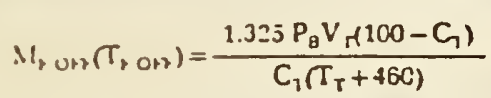

$P_{s}=$ t.arumetric pressisie measured in dccordarice with 3.6 of this appendix in inches of merrury

$V_{T}=$ flow raie of trace: gus through the ves.ced heater mejsured in accordance with 3.6 of this apperdix in cubic feet per minule

$C_{T}=$ concentration by volume of tracer gas present in the lue gas sample measured in accordance with 3.6 of this appendix in perceat

$\mathrm{C}_{\mathrm{T}}{ }^{\circ}=$ concentration by volume of the active traier 8.19 in the mixlure in percent and is 100 when the Iracer gas is a sirg!e component 8 as

$T_{8}=$ the temperal'ure of the tracer gas entering the flow meler measured in accordance

with 3.6 of this appendix in degrees Fdhrenteit

$\left(T_{r}+f C 0\right)=a b s n l u t e$ temperature of the tracer gas entusing the fow meter in degrees Kumb:ne

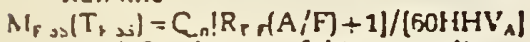

$Q_{.0}=$ as déned in 3.1 of this appendix

$R_{P f}=$ as defined in 4.1.7 of this appendix

$A / F=$ as derined in 4.22 of this appendix

$H I I V_{A}=$ as defined in 4.22 of this appendix

4.5.2 Optionol procedure for determining off-cicte dra, factor for flue gas flow for vented heciers. For systems numbered 1 thru 10. caicu!date the off cycle drait factor for flue

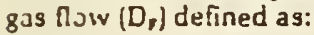

$D_{r}=D_{p}$

For systems numbered 11 or $12: D_{\mathrm{P}}=\mathrm{D}_{\mathrm{P}} \mathrm{D}_{\mathrm{O}}$ whier:

$D_{3}=$ as de.ined in 4.5.1. of this appendix $\mathrm{D}_{u}=$ as defined in 4.4 of this appendix

4.5.3 Optionol procedure for determining off-cycle droft factor for stcck gas flow for vented heaters. Calculate the off-cycle draft fuctor for stack alas flow $\left(D_{s}\right)$ defined as:

Fur sysiems numbered 1 or $2: D_{9}=1.0$

For systems numbered 3 or $4: D_{g}=\left(D_{p}+0.79\right) /$ 1.4

For systems numbered 5 or $6: D_{3}=D_{0}$

For sysiems numbered 7 or 8 and if $D_{u}(S /$ F) $\angle 1: D_{3}=D_{0} D_{p}$

For strsterns nusbered 7 or 8 and if $D_{0}(S /$ F) $>1$ :

$D_{S}=D_{u} D_{p}+\left[0.8 j-D_{v} D_{r} \mid\left\{D_{u}(S / F)-1\right] /(S)\right.$

F..11

where:

$D_{p}=$ as defined in 4.5 .1 of this appendix

$D_{0}=$ as refined in 4.4 of this a ppendix
Table 1.-OfF-Cycle DaAfT Factors for Fi: : UAS FLOW (Ds) AND FOR STACK GAS FLOW (Ds) FOR VENTEO HOME HEATING EOUIPMENT EOUIPPEO WIITHOUT THERMAL STACK DAMPERS

\begin{tabular}{|c|c|c|c|c|}
\hline $\begin{array}{l}\text { Srstem } \\
\text { number }\end{array}$ & $(Q)$ & $(0,1$ & Bumex & Venong system ros " \\
\hline 1. & 1.0 & 1.0 & Atmos & Dian nood or deveres. \\
\hline 2. & 0.4 & 10 & Power..... & Orall hood or Averter. \\
\hline 3. & 1.0 & $\begin{array}{r}1.0 \\
0.85\end{array}$ & $\begin{array}{l}\text { Aumos- } \\
\text { phers. } \\
\text { Powner. }\end{array}$ & $\begin{array}{l}\text { Baromatic of ah } \\
\text { regutator. } \\
\text { Beromatric draf }\end{array}$ \\
\hline 5 & 1.0 & o. & Aimos & $\begin{array}{l}\text { regilator. } \\
\text { Crati rood or diventer } \\
\text { with damper. }\end{array}$ \\
\hline 6 & 0.4 & D. & Power. & $\begin{array}{l}\text { Oran rood or diverter } \\
\text { with damosr. }\end{array}$ \\
\hline 7. & 1.0 & 0. & $\begin{array}{l}\text { Atmos } \\
\text { oherc }\end{array}$ & $\begin{array}{l}\text { Bammere of an } \\
\text { regutator min } \\
\text { omper. }\end{array}$ \\
\hline 9 & 1.0 & & Atmos & $\begin{array}{l}\text { regulato whe } \\
\text { damper. } \\
\text { Croct vente }\end{array}$ \\
\hline 10. & 0.4 & & Power - & Dract var \\
\hline 12 & $\begin{array}{l}0.4 \\
0 .\end{array}$ & & Power. & Diruct verte wath \\
\hline
\end{tabular}

table 3.-Fraction of heating load at REOUCED OPEAating nioce $\left(X_{1}\right)$ and at MaXimum OPERATING MOOE (X2), AVERAGE OUTOOOR TEMFERATJRES (TOA ANO TOA'). ano BalanCE POINT TEvfezatuRE (TC) FOR VENTEO HEATEAS EOUIPPED W/TH EMTHEA TWO-STAGE THERMOSTATS OA STEP-MOOULATI:NG THERMCSTATS

\begin{tabular}{|c|c|c|c|c|c|}
\hline Heat output rano. & $x_{i}$ & $\times 2$ & TOA & TOA & TC \\
\hline 0100.24 & .12 & .88 & 57 & $\infty$ & 53 \\
\hline 25 to $029 \ldots$ & $.1 \mathrm{e}$ & 6: & so & 39 & 51 \\
\hline $0.30100 .34 \ldots$ & 20 & 80 & $s$ & 38 & 49 \\
\hline $0.3510039 \ldots$ & .30 & .70 & 53 & 36 & 16 \\
\hline 0.40 to 0 -.......... & .38 & .84 & 52 & 35 & 4 \\
\hline 045 to $049 \ldots$ & 43 & .37 & si & 34 & 42 \\
\hline 0.50 to 0.54 & $\$ 2$ & .48 & 50 & 32 & 39 \\
\hline .55 & 60 & .0 & 49 & 30 & 37 \\
\hline $64 . \ldots$ & .70 & .30 & 48 & 29 & 34 \\
\hline 0.65 to 053. & .78 & 24 & 47 & 27 & 32 \\
\hline 0.70 to 0.74 & .64 & .16 & 46 & 25 & 23 \\
\hline 07.5 10 0.79 & 88 & .12 & 46 & 22 & 27 \\
\hline 0.80 to 0.84 & .24 & .08 & 45 & 20 & 23 \\
\hline $\begin{array}{l}0.8510089 . \\
0.95100 .94 .\end{array}$ & $\begin{array}{l}.96 \\
.98\end{array}$ & $\begin{array}{l}01 \\
.02\end{array}$ & 4 & $\begin{array}{l}18 \\
16\end{array}$ & $\begin{array}{l}21 \\
19\end{array}$ \\
\hline & .99 & 01 & 4 & 13 & 17 \\
\hline
\end{tabular}

- The hest culvur rado means the nido at mimum marameun heat outpur rates es dehned an 4.1.13.

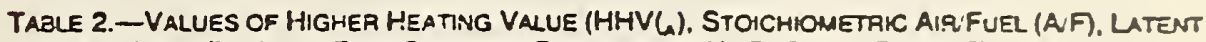
MEAT LOSS (LLA) APID FUEL-SPECIFIED PARAMETERS (A, B, C. AND O) FOA TYPICAL FUELS

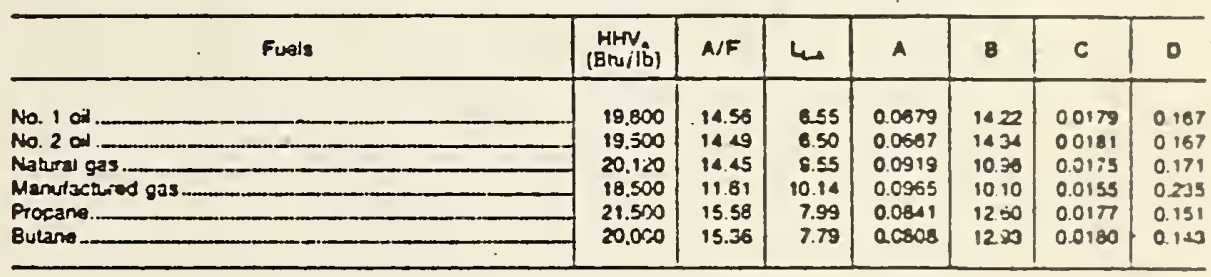




\section{FIGURE 1}

Average Outdoor Air Temperature vs. Balance Point Temperature for Modulating Vented Heaters

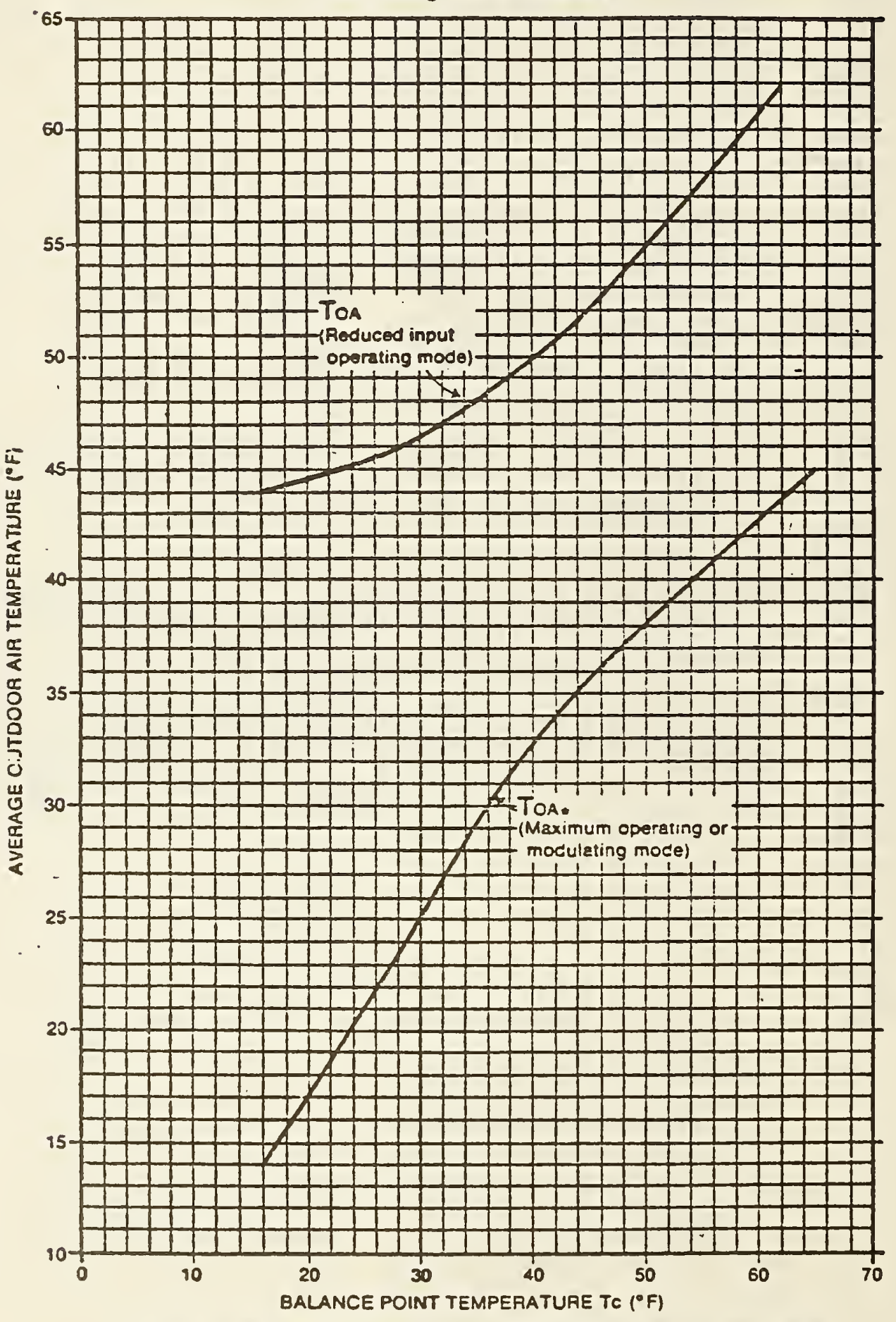

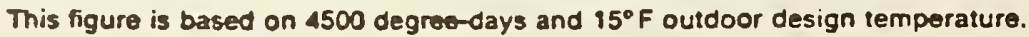


FIGURE 2

Fraction of Total Annual Heating Load Applicable to Reduced Operating Mode $\left(X_{1}\right)$ and to Maximum Operáting Mode or Modulating Mode $\left(X_{2}\right)$ vs. Balance Point Temperature for Modulating Vented Heaters

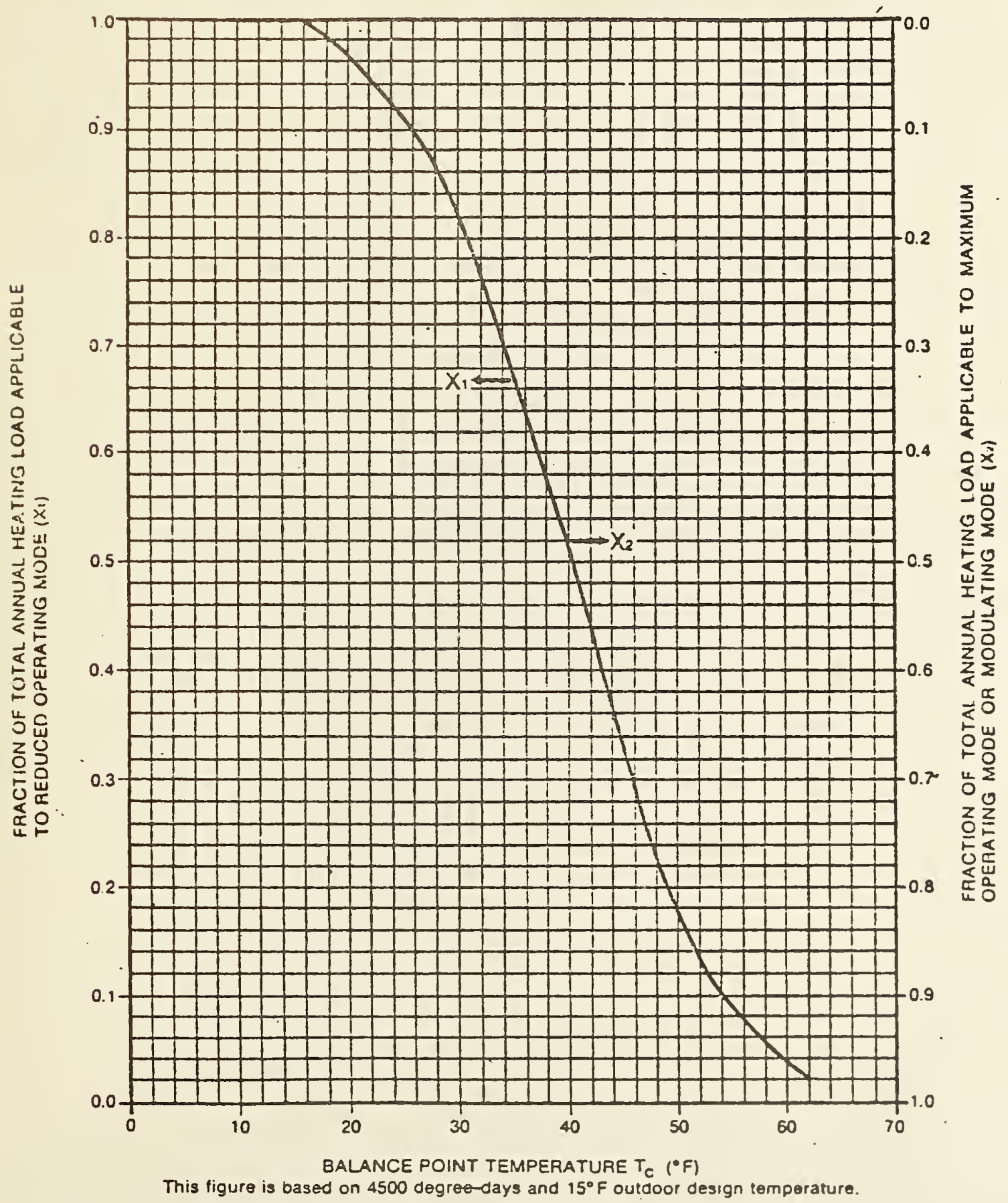

iF R Dur . B+7231 Filed 3-27-A4. B +5 am

BILLING CODE 6450-01-C 

APPENDIX C

EXAMPLES

Completed Input Form Input Files

Computer Runs 

Titia ${ }^{\prime} 1$ Assumed data to test program VENT, also check conversions

Iitlo HI $^{2}$ Two-stage modulating, with damper, measured off-loss.

\begin{tabular}{|c|c|c|c|c|c|}
\hline $\begin{array}{c}\text { Sjstem } \\
\mu\end{array}$ & $\begin{array}{c}\text { Fuel } \\
\mu\end{array}$ & $\begin{array}{c}\text { Control } \\
\mu\end{array}$ & $\begin{array}{c}\text { Option } \\
\mu\end{array}$ & $\begin{array}{c}\text { Fuel Cost } \\
\text { c/Therm. }\end{array}$ & $\begin{array}{c}\text { Elect. Cost } \\
\text { clkilh }\end{array}$ \\
\hline 5 & 3 & 2 & 3 & 64.6 & 7.63 \\
\hline
\end{tabular}

\begin{tabular}{|c|c|c|}
\hline $\begin{array}{c}\text { Pilot } \\
2+1 / 0: n^{*}\end{array}$ & $\begin{array}{c}\text { Elect. } \\
\mathrm{k}^{\top} /{ }^{*}\end{array}$ & $\begin{array}{l}\text { Jacket } \\
\text { Loss, of * }\end{array}$ \\
\hline 8.0 & 0.100 & 4.5 \\
\hline
\end{tabular}

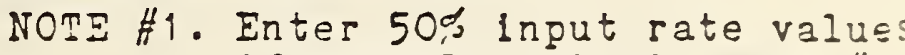
if manual control, type $\pi^{4}$ \#2. * ${ }^{*}$ enter 0.0 if not measurs:

\begin{tabular}{|c|c|c|c|c|c|}
\hline $\begin{array}{l}\text { Fu } \leq \text { I Input } \\
E \div, i d / \mathrm{m} \text { in. }\end{array}$ & $\begin{array}{l}\text { Room Amb. } \\
\text { F or C }\end{array}$ & $\begin{array}{l}\text { Stack Temp. } \\
\text { F or C }\end{array}$ & $\begin{array}{l}\text { Flue Temp. } \\
\text { F or } C^{*}\end{array}$ & Co2 Stack & Co2 Flue \\
\hline 800 & 22.22 & 193.3 & 263 & 6.5 & 10.0 \\
\hline
\end{tabular}

Enter next line only if tested at second (refuced) inout rate.

\begin{tabular}{l|l|l|l|l|l|}
\hline 400 & 21.5 & 143 & 157.5 & 5.5 & 8.5 \\
\hline
\end{tabular}

Enter next line only if with damoer and off-loss not measured.

\begin{tabular}{|c|c|c|}
\hline $\begin{array}{c}\text { Siaci Area } \\
\text { sa. } 1 \mathrm{n} .\end{array}$ & $\begin{array}{r}\text { Damper area } \\
\text { sa. in. }\end{array}$ & $\begin{array}{c}\text { Angle } \\
\text { deg. }\end{array}$ \\
\hline- & - & - \\
\hline
\end{tabular}

Enter next. Iine onIJ if draft measured (Do). ootion $\$ 2$.

\begin{tabular}{|c|c|c|c|c|c|}
\hline $\begin{array}{l}\text { Ea-omete? } \\
\text { "iz or mo }\end{array}$ & $\begin{array}{l}\text { Gas Temp. } \\
\text { F or C }\end{array}$ & $\begin{array}{l}\text { Gas Conc. } \\
\text { \% or Dom }\end{array}$ & $\begin{array}{l}\text { Gas Flow } \\
\text { cu.ft./min }\end{array}$ & $\begin{array}{l}\text { Trac. Conc. } \\
\text { o or oom }\end{array}$ & $\begin{array}{c}\text { Flue temp. } \\
\text { F or } \mathrm{C}\end{array}$ \\
\hline - & - & - & - & - & - \\
\hline
\end{tabular}

Entar next Iines only if measured high fire off-loss measured.

\begin{tabular}{|c|c|c|c|c|}
\hline \multicolumn{2}{|c|}{ 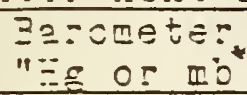 } & \multicolumn{2}{|c|}{$\begin{array}{l}\text { Gas Temp. } \\
F \text { or } C\end{array}$} & $\begin{array}{l}\text { Gas Cor } \\
\text { o or D }\end{array}$ \\
\hline \multicolumn{2}{|c|}{1001} & 20. & & 50800 \\
\hline $\begin{array}{c}\because \because 035 \\
\frac{\pi}{11}\end{array}$ & $\begin{array}{r}\text { T:ac } \\
\% 0 \\
\end{array}$ & $\begin{array}{l}\text { Conc. } \\
\text { Don }\end{array}$ & & $\begin{array}{l}=T \in M D . \\
\text { or } C\end{array}$ \\
\hline 1 & & .1 & & 61.6 \\
\hline 2 & & .3 & & 25.8 \\
\hline 3 & & 6 & & 100.3 \\
\hline 4 & & .6 & & 84.9 \\
\hline 5 & & .5 & & 76.8 \\
\hline 6 & & 7.8 & & 70.7 \\
\hline$\approx$ & & 3 & & 65.8 \\
\hline 2 & 10 & .0 & & 61.3 \\
\hline 3 & 10 & 5 & & 57.9 \\
\hline 16 & & .8 & & 54.9 \\
\hline
\end{tabular}

Enter next lines only if reduced fire off-loss measured.

\begin{tabular}{|c|c|c|c|c|}
\hline \multicolumn{2}{|c|}{$\begin{array}{l}\text { בa:ocetar } \\
" \because g \text { or mb" }\end{array}$} & \multicolumn{2}{|c|}{ Gas Temo. } & $\begin{array}{l}\text { Gas Con } \\
\text { of or Do }\end{array}$ \\
\hline \multicolumn{2}{|c|}{0.0} & 20.5 & & 508000 \\
\hline$\because \underset{4}{4}=35$ & $\begin{array}{l}\text { Ir } 30 \\
80\end{array}$ & $\begin{array}{l}\text { - Conc. } \\
r \quad 00 m\end{array}$ & Fl & $\begin{array}{l}\text { e temp. } \\
\text { or C }\end{array}$ \\
\hline 1 & & 0.5 & & 95.2 \\
\hline$\stackrel{2}{2}$ & & 1.1 & & 69.8 \\
\hline$\overline{3}$ & & +7.0 & & 55.2 \\
\hline$\leq$ & & 0.2 & & 45.1 \\
\hline$\equiv$ & & .7 .8 & & 42.1 \\
\hline$\underline{E}$ & & 6.9 & & 40.0 \\
\hline $\bar{i}$ & & 4.1 & & 39.0 \\
\hline$\Xi$ & & 88.9 & & 36.9 \\
\hline g. & & 03,5 & & 35.3 \\
\hline 10 & & 13.3 & & 34.6 \\
\hline
\end{tabular}


1 Assumed data to test program VENT, also check conversions.

2 Two-stage modulatirig, with damper, measured off-loss.

$\because 532364.67 .63$

48.14 .5

$5800 \quad 22.22 \quad 193.3 \quad 263 \quad 6.510 .0$

$640021.5143 \quad 157.5 \quad 5.5 \quad 8.5$

7100120.5508000 .00073999

3 $73.1 \quad 1 \leqslant 1.6$

775.3125 .8

1077.6100 .3

11. 77.6 .94 .9

1278.576 .8

$137 \% .870 .7$

1488.365 .8

15100.061 .3

16104.557 .9

17106.854 .9

19020.5508000 .00057 Default barometric pressure

19120.575 .2

20131.169 .3

21. 147.055 .2

22160.245 .1

$2.67 .5 \quad 42.1$

24176.940 .0

$25 \quad 1.4 .1 \quad 3 \% .0$

26180.96 .9

27203.535 .3

$20213.3 \quad 34.6$

ENII IF FILE

$-9$ 
Iriput dati, trpe-"eAII FILENAME. ELEMENTNAME"

>eadd tstdat. vritst7

VENTED HEATER TEST REPORT

Assumed data ta test program VENT, also check coriversions.

Two-stage madulating, with damper, measured off-loss.

$* * * * * * * * * *$ INPUT SELECTIONS $* * * * * * * * * * *$

SYSTEM \# FIIEL CONTRUL OFTIONS FUEL-COST ELECT-COST
5
3
2
3
\$4. 60
7.63

WITH FILIT LIGHT, RF=ETII/MIN. = E.O

ELECTFII FRWER, KW=.100

IACKET LISS, \% LISSE= 4.50

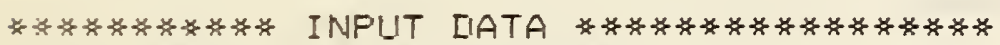

HISHH FUEL INFUIT RATE DATA

INFUT AMB TEMP TEMF CDZ CQZ

BTI/MIN TEMP STACK FLUE STACK FLUE

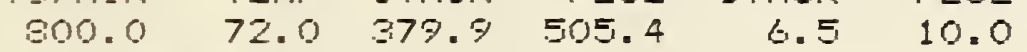

LOW FIJEL INPIIT RIATE
400.0
$70.7 \quad 289.4 \quad 315.5$
5.5
8.5

HIGH FIRE UFF-LIEG DATA.

BAFII. TEMF. CONE: VOLM. TINC. TEMP.

FFIES: TRAR: TRAR. TRAC. FLUE FLUE

$30.4 b \quad 38.9 \quad .51+006 \quad .73-003 \quad .73+002 \quad 322.9$

$.75+002 \quad 258.4$

$.78+002 \quad 212.5$

$.73+002 \quad 184.8$

$.78+002 \quad 170.2$

$.80+0021.59 .3$

$.35+002150.4$

$.10+003142.3$

$.10+003136.2$

LOW FIRE IFF-LISS IIATA.

$.11+00.3 \quad 130.8$

$\begin{array}{lllllll}30.00 & 68.9 & .51+006 & .57-003 & .12+003 & 203.4\end{array}$

$.13+003 \quad 157.6$

$.15+003 \quad 131.4$

$.16+003 \quad 113.2$

$.17+003 \quad 107.8$

$.18+003 \quad 104.0$

$.18+003 \quad 102.2$

$.19+00398.4$

$.20+003 \quad 95.5$

$.21+003 \quad 94.3$

LOW HEAT FFACTION=.520 HICHH HEAT FRACTION=.480

BALANEE FCIINT TEMP. $=\$ \% .42$

$L S, I \Gamma_{1}=9.53 \quad L i, C_{1}=.90$

L5, off $=$. Eb Li, off $=.25$

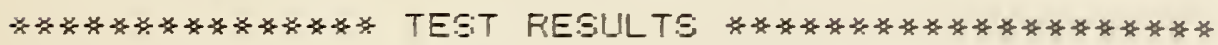

WEIGHTEI SITEADY SITATE EFF ICIENEY $=80.72 \%$

AFUE $=65.03 \%$

COGT/MILLION BTI= 10.11 
Temperatures in degrees Fahrenheit

tstiat. vtitsto

1 Assumed data to test program VENT

2 Eingle stage, with damper, measured off-loss.

3531364.77 .63

48.14 .5

$5800,72,380,505.5,6.5,10.0$

61000.70 .0508000 . 0.00078398

773.1322 .9

(3) 75.3258 .4

5 $77.6 \quad 212.5$

1077.6184 .3

1178.5170 .2

1279.8159 .3

158.3150 .4

14100.0142 .3

15104.5136 .2

16106.9130 .8

ENII DF FILE

$-3$ 
Iriput data, trpe-"eAIII FILENAME. ELEMENTNAME"

sadd tstdat. vitsts

\section{VENTEI HEATEF TEST REFIIFT}

Assumed data to test program VENT

Sirigle stage, with damper, measured aff-iass.

*********** INPIIT SELEITTIONS: ***********

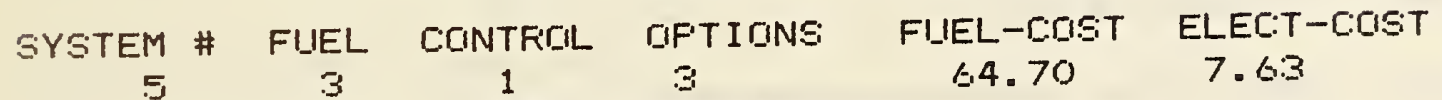
5
3

WITH FILUT LIFIHT, RF=BTLI/MIN. $=8.0$

ELEC:TRIC FCIWER, KW $=.100$

IAC:KET LUES, \% LUSS= 4.50

********** INPIIT IIATA *****************

HICIH FIIEL INFIUT FIATE IIATA

INFUIT AME TEMF TEMF C:I2 C.I2

BTU/MIN TEMF STACK FLLE STACK FLLIE

800.0 $72.0 \quad 380.0 \quad 505.5 \quad 6.5 \quad 10.0$

HIGH FIRE DFF-LOSE IIATA.

BAFI. TEMF. COINC. VCILM. CONC. TEMF.

FRES. TRAC: TFAC. TRAC. FLUE FLIIE

$30.43 \quad 70.0 \quad .51+006.79-003.73+002 \quad 322 . \%$

$.75+002 \quad 256.4$

$.78+002 \quad 212.5$

$.78+002184.8$

$.78+002 \quad 170.2$

$.30+002 \quad 159.3$

$.86+002 \quad 150.4$

$.10+003 \quad 142.3$

$.10+003 \quad 136.2$

$.11+003 \quad 130.8$

Ls, $\Delta \Pi_{1}=10.51 \quad$ Li,on $=.04$

LS, off $=1.30 \quad$ Li, off $=.24$

************* TEST RESULTS *******************

WEITHHTEI GTEAIY STATE EFFICIENC:Y $=79.94 \%$

AFIJE $=73.62 \%$

C:CIST/MILLION ETU $=\$ 8.92$ 
Assumed data to test program VENT

Single stage, minimum testing.

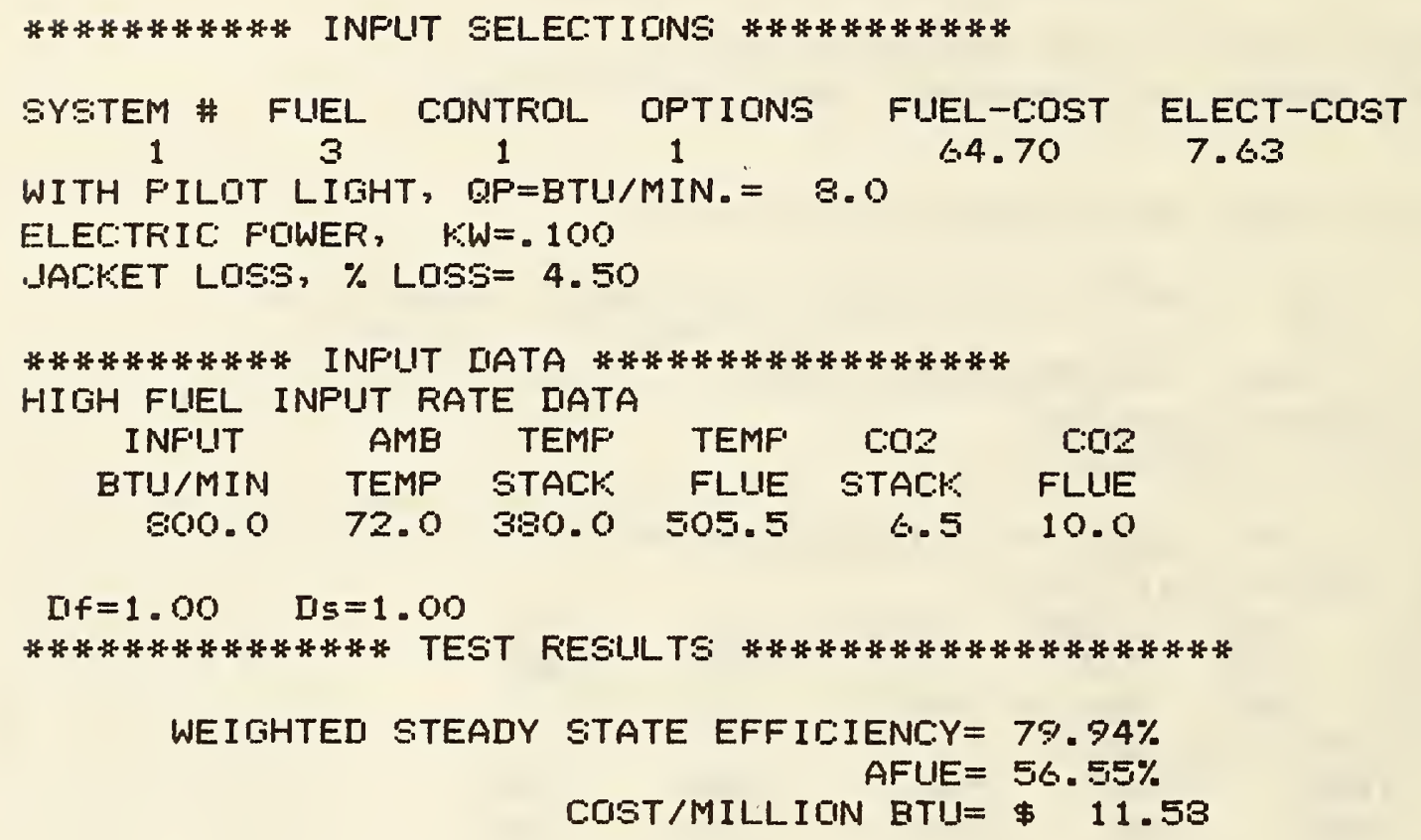

AFUE $=(.968 * 79.94)-1.78-1.84-\left(\frac{129 . * 80}{800}\right)-(3.93 * 4.5)+1.81=56.6 \%$ 
Assumed data to test program VENT

Manual-on off, mirimum testing.

*********** INFIIT SELECTIINS ***********

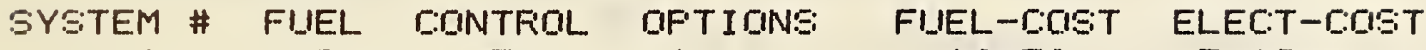
1
3
5
1 54.70
7.63

WITH FILOT LICIHT, GF=ETU/MIN. = 8.0

ELEC:TFIC FOWEF, $K W=.100$

-IACKET LUES, \% LOGS= 4.50

********* INPUT IIATA ****************

HICIH FUEL INFUIT RATE IIATA

INFITT AME TEMF TEMF C:02 $\mathrm{COZ}$

ETIIIMIN TEMF STAEK FLUE STACK FLUE

$\begin{array}{llllll}900.0 & 72.0 & 380.0 & 505.5 & 6.5 & 10.0\end{array}$

Li, $\Delta r_{1}=.04$

************** TEST FIESULTSI ********************

WEIOHTED STEADY STATE EFFICIENCY $=7 \% .94 \%$

AFUE $=6.5 .95 \%$

COST/MILLION BTIJ=\$ $\% .96$

$$
\begin{aligned}
& \eta_{u}=\eta_{s s}-L_{i, 0 N}-C_{j} * L_{j}=70.04-.04-(2.8 * 4.5)=67.3 \% \\
& A F \cup E=\frac{n_{.0}}{1+\left(2.61 * \frac{n_{v}}{n_{1}} * \frac{Q_{H}}{Q_{1 N}}\right)} \\
& =\frac{67.3}{1 .\left(2.6 * \frac{67.3}{79.94} * \frac{8}{830}\right)}=65.85 \%
\end{aligned}
$$

$$
\text { Without } \begin{aligned}
C_{T}^{*} L_{J} \quad n_{U} & =79.90 \mathrm{7J} \\
\text { AFVE } & : 77.87 \% \\
1 / 1 & =8.44
\end{aligned}
$$


Assumed data to test program VENT

Marual-adjustable fuel rate, minimum testirig.

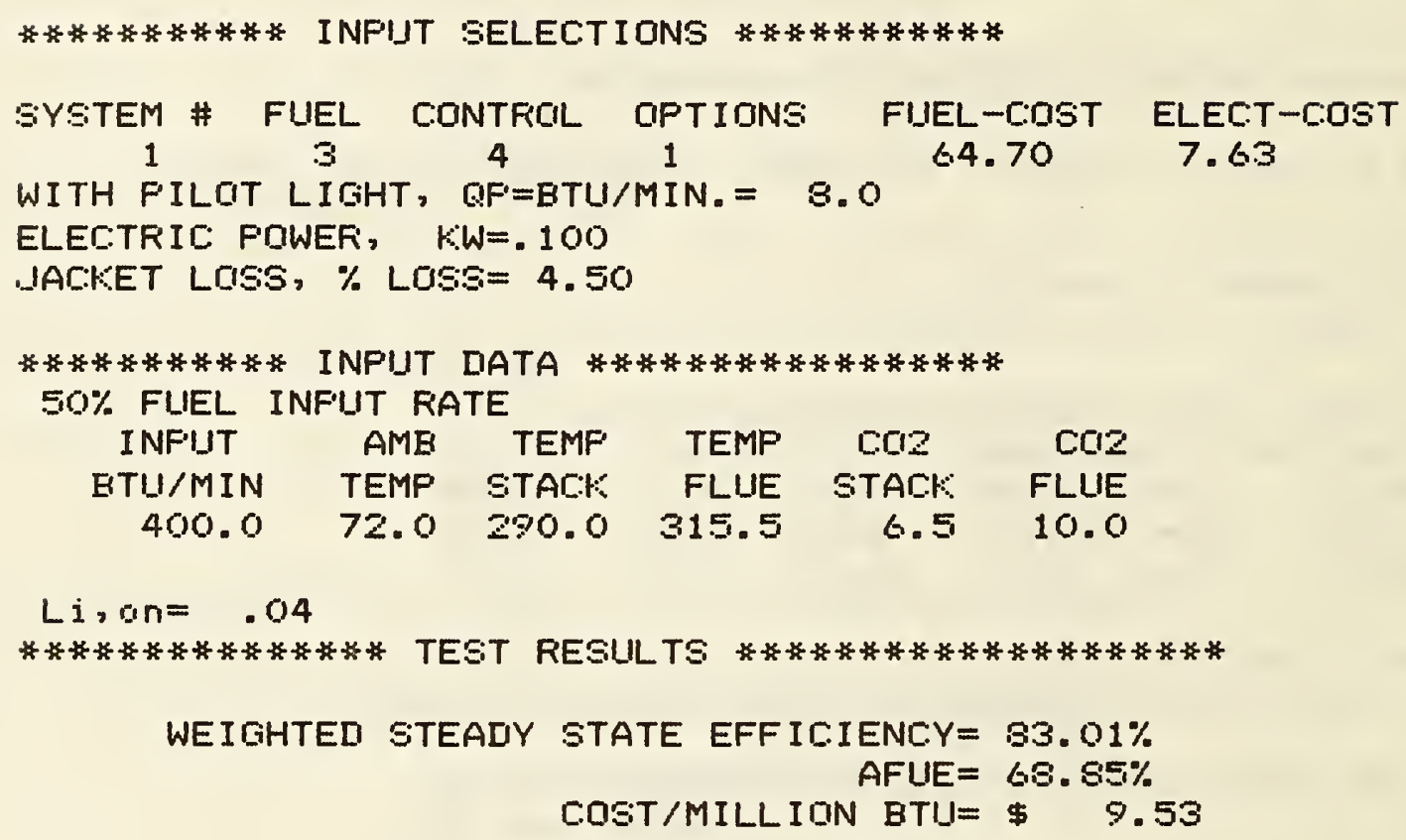


VENTEI HEATER TEST REFORT

Assumed data to test program VENT

Single stage, mirimum testirı, with damper.

*********** INPIIT SELEITI INSS***********

SYGTEM \# FLEL CONTRROL DPTIONS FIJEL-COST ELECT-COST

$\begin{array}{llllll}5 & 3 & 1 & 1 & 64.70 & 7.63\end{array}$

WITH PILOT LIGHT, QIF $=$ BTUIMIN. $=8.0$

ELECTRIC FOIWEF, KW $=.100$

JACKET LOSS, \% LUSS= 4.50

********** INFUT IIATA ***************

HIGH FLIEL INFUT FIATE IIATA

INPUT AME TEMP TEMP $\mathrm{C:O2}$ C:CI2

BTU/MIN TEMF STACK FLUE STACK FLIE

$800.0 \quad 72.0 \quad 380.0 \quad 505.5 \quad 6.5 \quad 10.0$

IIAMPER DATA: DAMPER AREA $=28.00, \Xi T A C K$ AREA $=26.80$ ANGLE $=25.0$ $[I 0=.21$

Df $=1.00 \quad[\mathrm{Is}=.21$

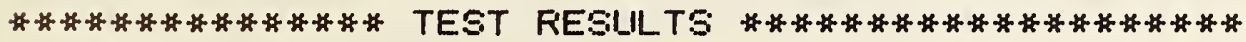

WEIGHTED STEADY STATE EFFICIENCY $=7 \% . \% 4 \%$

AFIJE $=58.04 \%$

[OST/MILLIIN BTIJ= $\$ 11.28$ 


\section{VENTEI HEATEF TEST REFOFT}

Assumed data to test program VENT

Eingle stage, with damper, measured draft factor.

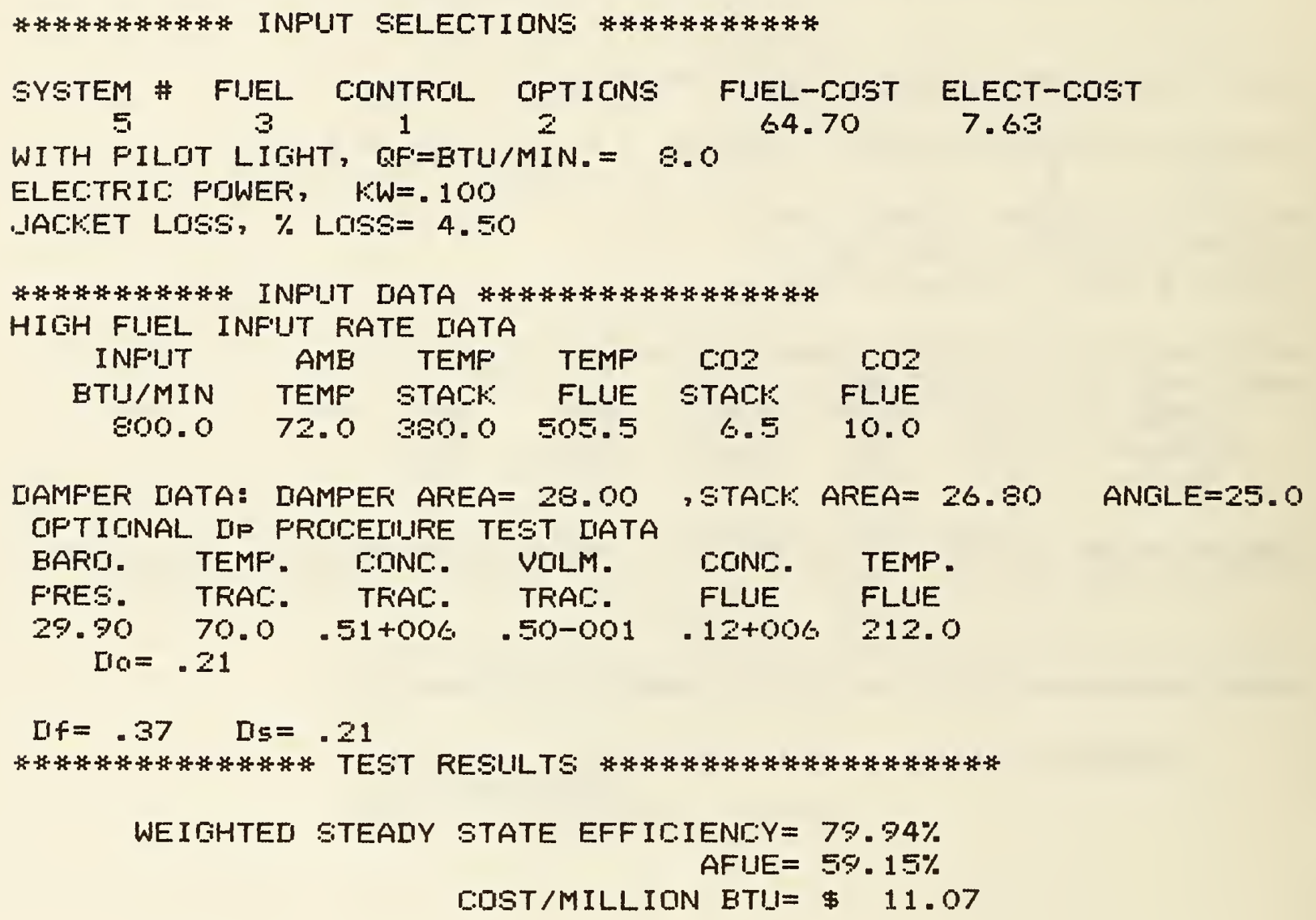


1. PUBLICATION OR REPORT NO. NBSIR 84-2918
2. Performing Organ. Report No.

3. Publication Date

September 1984

BIBLIOGRAPHIC DATA

SHEET (See instruction s)

4. TITLE AND SUBTITLE

Fortran 77 Computer Program for Test Procedure Calculations of Vented Heaters

5. $A \cup T H O R(S)$

R. A. Wise, F. C. Parsons

6. PERFORMING ORGANIZATION (If joint or other than NBS, see instructions)

NATIONAL BUREAU OF STANDARDS

DEPARTMENT OF COMMERCE

WASHINGTON, D.C. 20234

9. SPONSORING ORGANIZATION NAME AND COMPLETE ADDRESS (Street, City, State, ZIP)

Department of Energy

Forrestal Building

1000 Independence Avenue

Washington, DC 20585

10. SUPPLEMENTARY NOTES

Document describes a computer program; SF-185, FIPS Software Summary, is attached.

11. ABSTRACT (A 200-word or less foctual summary of most significant information. If document includes a significant bibliography or literature survey, mention it here)

The Fortran 77 computer program described in this report is to be used to calculate results from tests run on vented heaters. The Department of Energy recently published a revised test procedure for such heaters but which contains a simplified method for testing with a number of testing options that allow more detailed tests to be run. The new procedure also provides for the testing of units with manual controls of two types, modulating controls of two types, and the testing of units incorporating thermal stack dampers as well as electro-mechanical dampers. Once input selections have been made, the program performs the calculations required and prints out the results.

12. KEY WORDS (Six to twelve entries; alphabetical order; capitalize only proper names; and separate key words by semicolons) Computer program; energy; test procedure; vented heaters; furnace

13. AVAILABILITY

X] Unlimited

$\square$ For Official Distribution. Do Not Release to NTIS

Order From Superintendent of Documents, U.S. Government Printing Office, Washington, D.C. 20402.

[X] Order From National Technical Information Service (NTIS), Springfield, VA.
14. NO. OF

PRINTEO PAGES 53

15. Price 


